\title{
Development of an inversion method to extract information on fault geometry from teleseismic data
}

\author{
Kousuke Shimizu, ${ }^{1}$ Yuji Yagi, ${ }^{2}$ Ryo Okuwaki, ${ }^{2}$ and Yukitoshi Fukahata ${ }^{3}$ \\ ${ }^{1}$ Graduate School of Life and Environmental Sciences, University of Tsukuba, Tsukuba, Ibaraki 305-8572, Japan. \\ E-mail:smzksk@geol.tsukuba.ac.jp \\ ${ }^{2}$ Faculty of Life and Environmental Sciences, University of Tsukuba, Tsukuba, Ibaraki 305-8572, Japan. \\ ${ }^{3}$ Disaster Prevention Research Institute, Kyoto University, Uji, Kyoto 611-0011, Japan.
}

\section{SUMMARY}

Teleseismic waveforms contain information on fault slip evolution during an earthquake, as well as on the fault geometry. A linear finite-fault inversion method is a tool for solving the slip-rate function distribution under an assumption of fault geometry as a single or multiple-fault-plane model. An inappropriate assumption of fault geometry would tend to distort the solution due to Green's function modelling errors. We developed a new inversion method to extract information on fault geometry along with the slip-rate function from observed teleseismic waveforms. In this method, as in most previous studies, we assumed a flat fault plane, but we allowed arbitrary directions of slip not necessarily parallel to the assumed fault plane. More precisely, the method represents fault slip on the assumed fault by the superposition of five basis components of potency-density tensor, which can express arbitrary fault slip that occurs underground. We tested the developed method by applying it to real teleseismic $P$ waveforms of the $M_{\mathrm{W}} 7.72013$ Balochistan, Pakistan, earthquake, which is thought to have occurred along a curved fault system. The obtained spatiotemporal distribution of potency-density tensors showed that the focal mechanism at each source knot was dominated by a strike-slip component with successive 
strike angle rotation from $205^{\circ}$ to $240^{\circ}$ as the rupture propagated unilaterally towards the south-west from the epicentre. This result is consistent with Earth's surface deformation observed in optical satellite images. The success of the developed method is attributable to the fact that teleseismic body waves are not very sensitive to the spatial location of fault slip, whereas they are very sensitive to the direction of fault slip. The method may be a powerful tool to extract information on fault geometry along with the slip-rate function without requiring detailed assumptions about fault geometry.

Key words: Image processing; Time-series analysis; Inverse theory; Earthquake dynamics; Earthquake source observations

\section{INTRODUCTION}

In general, the seismic waveform contains information on the spatiotemporal moment density tensor distribution. This means that information on the slip-rate function, rupture extent, and fault geometry is included in the seismic waveform. Finite-fault inversion of seismic waveforms, a tool that can be used to estimate the spatiotemporal slip-rate distribution of an earthquake, has been used to analyse seismicsource processes since the 1980s (e.g. Olson \& Apsel 1982; Hartzell \& Heaton 1983). However, the non-uniqueness of the source models for the same earthquake obtained by different inversion schemes has been an issue in seismic source inversion studies (e.g. Beresnev 2003; Mai et al. 2016). Simplified assumptions of Earth's structure and fault geometry are dominant sources of modelling errors. Modelling errors tend to distort solutions if we neglect it (e.g. Yagi \& Fukahata 2008, 2011), which can be one of the causes of the non-uniqueness and may critically affect the interpretation of rupture process.

The major source of modelling errors is the uncertainty in Green's functions; that is, a discrepancy between the true and the calculated Green's function due to inaccuracy of the Earth's structural model (e.g. Yagi \& Fukahata 2011). Several inversion schemes have been developed to mitigate the effects of uncertainty in Green's functions by introducing the uncertainty into the data covariance matrix (Yagi \& Fukahata 2011; Minson et al. 2013; Duputel et al. 2014). Yagi \& Fukahata (2011) showed that their formulation made it possible to stably estimate the slip-rate function without forcing nonnegative slip, which had been the common constraint to obtain stable estimate of slip (e.g. Du et al. 1992; Freymueller et al. 1994). Minson et al. (2013) also proposed a stable inversion method without a smoothing constraint as a prior probability-density function, although an implicit smoothing constraint that forces constant slip on each source knot is still imposed in their method (e.g. Bodin et al. 2009; 
Nocquet 2018). These studies have opened a window into a stable and flexible seismic source inversion method that requires fewer prior constraints by more properly evaluating errors included in the seismic source inversion.

Another major source of the modelling errors is uncertainty in fault geometry. A simplified, inappropriate approximation of fault geometry by a flat or curved model plane may lead to inappropriate source models even if the uncertainty in Green's functions is taken into account, especially for an earthquake that occurs in a geometrically complex fault system (e.g. Gombert et al. 2018; Ragon et al. 2018). Ragon et al. (2018) introduced the uncertainty in fault geometry into the data covariance matrix based on the framework of Duputel et al. (2014), making it possible to robustly estimate the slip distribution even under an assumption that the approximated fault geometry is slightly fluctuated from the true one. The introduction of the uncertainty in fault geometry into an inversion scheme may contribute to constructing an unbiased source model, but is not designed to extract the information on fault geometry, which is included in the observed data (e.g. Fukahata \& Wright 2008; Minson et al. 2014; Chen et al. 2014; Zhang \& Wang 2015; Duputel \& Rivera 2017; Shi et al. 2018). Information on the fault geometry is valuable for understanding the details of rupture propagation because discontinuities or spatial variations in the fault geometry play an important role in the rupture propagation (e.g. Aki 1979; Okuwaki \& Yagi 2018), especially for earthquakes such as the 2008 Wenchuan, China $\left(M_{\mathrm{W}} 7.9\right)$, the 2013 Balochistan, Pakistan $\left(M_{\mathrm{W}} 7.7\right)$, and the 2016 Kaikoura, New Zealand $\left(M_{\mathrm{W}} 7.8\right)$ earthquakes, which occurred in geometrically complex fault systems. In order to reveal the relationship between the geometrical complexity of a fault and the rupture propagation, the finitefault inversion framework adopting finely discretized model-source space is preferable, rather than the multiple-point-source inversions (e.g. Kikuchi \& Kanamori 1991; Duputel et al. 2012).

In this study, we propose a new finite-fault inversion framework of teleseismic waveforms to estimate both the fault geometry and the shear-slip evolution by introducing the Green's function uncertainty into the data covariance matrix (Yagi \& Fukahata 2011) and by increasing the number of shear-slip components from two to five, which can represent arbitrary direction of shear-slip direction (i.e. the direction of shear-slip is not confined on the assumed fault plane). It is generally difficult to estimate both a complex fault geometry and the shear-slip evolution simultaneously because of the non-linearity of the inverse problem to be solved (e.g. Fukahata \& Wright 2008; Ragon et al. 2018). However, the teleseismic waveforms are insensitive to an assumed spatial location of shear-slip but sensitive to an assumed direction of shear-slip. Hence, we can estimate the spatiotemporal variation of focal mechanisms along the model plane, which represents the information on the true fault geometry. Possible bias in the seismic source image due to an inappropriate assumption of fault geometry can be 
(a) This study

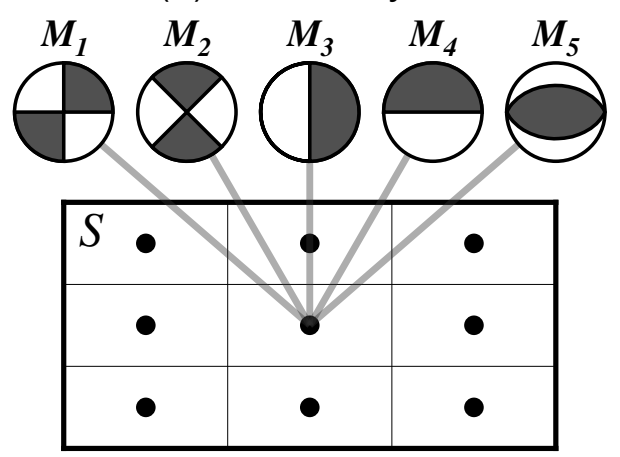

(b) Conventional

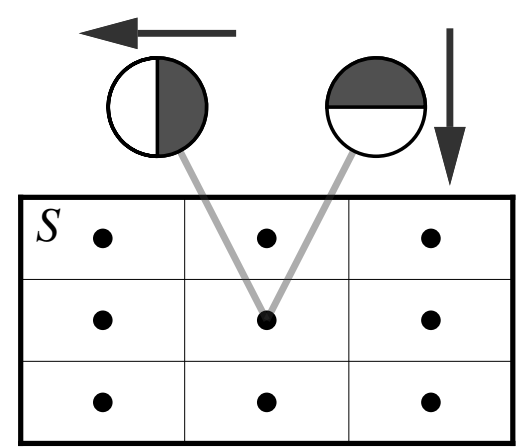

Figure 1. Representations of shear-slip at each source knot along a model plane $S$ by (a) our proposed method and (b) conventional method. Each dot represents a source knot located at the centre of each sub-fault on the model plane $S$. (a) The five beach balls denote the five basis components of double-couple moment tensor (Kikuchi \& Kanamori 1991); each component corresponds to a shear dislocation source, but is not needed to be parallel to the model plane $S$. The moment tensors, plotted by using a lower-hemisphere stereographic projection, are not rotated according to the model plane setting. (b) The two beach balls denote the two basis components of double-couple moment tensor that correspond to the shear dislocation sources along the model plane $S$. Arrows denote the slip directions of the two double-couple components whose nodal planes correspond to model plane $S$. The two moment tensors, plotted by using a lower-hemisphere stereographic projection, are rotated so that their one nodal planes correspond to model plane $S$; therefore, they do not correspond to $\boldsymbol{M}_{3}$ and $\boldsymbol{M}_{4}$ (projected in (a)).

significantly reduced in our proposed inversion framework that can represent the shear-slip direction independently from the assumed model fault plane.

We applied the developed method to the $M_{\mathrm{W}} 7.72013$ Balochistan, Pakistan, earthquake. Detailed analyses of the optical satellite images following this earthquake had revealed a curved fault geometry consistent with the tectonic fabric around the potential source area (Avouac et al. 2014; Barnhart et al. 2014; Jolivet et al. 2014; Zinke et al. 2014). We expected that the complex curved fault geometry of the 2013 Balochistan earthquake would help us to evaluate our new method that solves the spatiotemporal evolution of the potency-density tensor (e.g. Ampuero \& Dahlen 2005).

\section{MATHEMATICAL FORMULATION}

Earthquake sources can be generally represented by volume density of moment-rate tensors $\dot{\boldsymbol{M}}(t, \xi)$ (e.g. Backus \& Mulcahy 1976), which is expressed by a linear combination of five basis double-couple 
components $\boldsymbol{M}_{q}$ (Kikuchi \& Kanamori 1991) (Fig. 1a):

$$
\dot{\boldsymbol{M}}(t, \xi)=\sum_{q=1}^{5} \dot{m}_{q}(t, \xi) \boldsymbol{M}_{q},
$$

where "five" corresponds to the degree of freedom of the moment-rate tensor without isotropic expansion sources, $\dot{m}_{q}(t, \xi)$ is a spatiotemporal moment-rate volume-density function of $q$ th basis component of moment tensor, and $\xi$ represents a location in the source area. In a conventional scheme of finite-fault inversion, we solve a slip-rate function at each source knot with one or two directions of shear-slip on the assumed fault plane (e.g. Olson \& Apsel 1982; Ide et al. 1996; Ji et al. 2002), which is equivalent to solving the potency-rate areal-density function for two double-couple components (Fig. 1b), where the potency rate corresponds to the moment rate divided by the rigidity of the medium. As shown in Fig. 1b, one of the two nodal planes is constrained by the model fault plane in the conventional scheme. In this study, however, we propose a formulation for finite-fault inversion of teleseismic waveforms that solves the potency-rate areal-density function for five double-couple components (Fig. 1a), based on the framework of Yagi \& Fukahata (2011).

We represent a seismic waveform $u_{j}$ for a far-field term observed at a station $j$ by a linear combination of moment-rate volume-density functions of five basis components of double-couple moment tensor (Fig. 1a):

$$
u_{j}(t)=\sum_{q=1}^{5} \int_{V} G_{q j}^{0}(t, \xi) * \dot{m}_{q}(t, \xi) d \xi+e_{b j}(t),
$$

where $V$ is a three-dimensional source area, $G_{q j}^{0}$ is a Green's function, $e_{b j}$ is a background and instrumental noise, and $*$ denotes the convolution operator in the time domain. Eq. (2) requires the model source space to have three dimensions so as to represent the spatiotemporal moment-rate volumedensity distribution. In order to further represent the three-dimensional source area as a simple finitefault model in two dimensions, we assume that a finite-fault model obtained by a teleseismic body wave inversion is not seriously affected by a slight change of source location of the Green's function:

$$
G_{q j}^{0}(t, \xi+\delta \xi) \approx G_{q j}^{0}(t, \xi)
$$

where $\xi+\delta \xi$ is a neighbouring location around $\xi$. In fact, however, Green's function can change with source depth to some degree (e.g. Yagi et al. 2012). Through the synthetic tests, we evaluated the sensitivity to a slight change of source depth and confirmed that the change of source depth does not seriously affect the estimated distribution of focal mechanisms and overall features in the source-time function (Supporting Information Text. S1 and Fig. S9).

The approximation of eq. (3) makes it possible to change the volume integral to a surface integral 
on a model plane $S$ embedded in the source area $V$. Then, eq. (2) becomes

$$
u_{j}(t)=\sum_{q=1}^{5} \int_{S} G_{q j}^{0}(t, \xi) * \dot{m}_{q}^{\prime}(t, \xi) d \xi+e_{b j}(t),
$$

where $\dot{m}_{q}^{\prime}(t, \xi)$ is the moment-rate areal-density function, which is the projection of the volume density of the moment-rate function $\dot{m}_{q}$ on the flat-model plane $S$.

The moment-rate areal-density function is represented by the potency-rate areal-density function $\dot{D}_{q}:$

$$
\dot{m}_{q}^{\prime}(t, \xi)=\mu(\xi) \dot{D}_{q}(t, \xi)
$$

where $\mu(\xi)$ is the rigidity.

By substituting eq. (5) into eq. (4), we represent the observed waveform $u_{j}$ by the potency-rate areal-density function $\dot{D}_{q}$ :

$$
u_{j}(t)=\sum_{q=1}^{5} \int_{S} \tilde{G}_{q j}(t, \xi) * \dot{D}_{q}(t, \xi) d \xi+e_{b j}(t),
$$

with

$$
\tilde{G}_{q j}(t, \xi)=\mu(\xi) G_{q j}^{0}(t, \xi)
$$

Eq. (6) means that the distribution of potency-rate areal-density tensors can be estimated in the framework of the finite-fault inversion method. The slip rate corresponds to potency-rate areal density where a shear plane and its area are explicitly given, and the potency-rate areal density is equal to the slip rate if the slip direction of the potency-rate areal-density tensor lies on the model plane $S$.

In the conventional formulation, one of the two nodal planes determined by the two basis components of double-couple potency tensor corresponds to the model plane $S$, which means that the fault geometry is approximated by the model plane $S$ (Fig. 1b). While in this study, we adopt $q=5$ for the potency-rate areal-density function in eq. (6), which means that the shear plane is resolved with the five basis double-couple components of the potency-rate areal-density tensor, and it is therefore no longer required to be consistent with an arbitrarily presumed model plane geometry (Fig. 1a).

Following the multiple-time-window inversion method (e.g. Olson \& Apsel 1982), we represent the potency-rate areal-density function $\dot{D}_{q}$ by a linear combination of a finite number of basis functions:

$$
\dot{D}_{q} \cong \sum_{k=1}^{K} \sum_{l=1}^{L} a_{q k l} X_{k}(\xi) T_{l}\left(t-t_{k}\right),
$$

where $X_{k}$ and $T_{l}$ are the basis functions for space and time, respectively, and $a_{q k l}$ are the expansion 
coefficients (model parameters) to be estimated from the observed waveform data. $t_{k}$ is the time at which rupture can start on a space knot $k$.

By substituting eq. (8) into eq. (6), we can represent the observed waveform $u_{j}$ by the basis functions of space and time:

$$
u_{j}(t)=\sum_{k=1}^{K} \sum_{l=1}^{L} \sum_{q=1}^{5} a_{q k l} \int_{S} \tilde{G}_{q j}(t, \xi) *\left(X_{k}(\xi) T_{l}\left(t-t_{k}\right)\right) d \xi+e_{b j}(t) .
$$

Following Yagi \& Fukahata (2011), we introduce the modelling error of Green's function $\delta G_{q j}$ as

$$
\tilde{G}_{q j}(t, \xi)=G_{q j}(t, \xi)+\delta G_{q j}(t, \xi)
$$

We can rewrite eq. (9) by using the modelling error of Green's function $\delta G_{q j}$ :

$$
u_{j}(t)=\sum_{k=1}^{K} \sum_{l=1}^{L} \sum_{q=1}^{5} a_{q k l} \int_{S}\left(G_{q j}(t, \xi)+\delta G_{q j}(t, \xi)\right) *\left(X_{k}(\xi) T_{l}\left(t-t_{k}\right)\right) d \xi+e_{b j}(t) .
$$

The observation equation at the $j$ th station can be expressed in vector form as

$$
\boldsymbol{d}_{j}=\boldsymbol{H}_{j} \boldsymbol{a}+\boldsymbol{e}_{g j}(\boldsymbol{a})+\boldsymbol{e}_{b j}
$$

where $\boldsymbol{d}_{j}$ is the $N_{j}$ (number of data point at the $j$ th station) dimensional data vector that represents the observed waveform $u_{j}, \boldsymbol{a}$ is the $M(=5 K L)$ dimensional model parameter vector, $\boldsymbol{H}_{j}$ is the $N_{j} \times M$ dimensional coefficient matrix that represents convolutions of the calculated Green's functions and time-domain basis functions, $\boldsymbol{e}_{g j}$ is the $N_{j}$ dimensional vector that represents the modelling error of Green's function, and $\boldsymbol{e}_{b j}$ is the $N_{j}$ dimensional vector that represents the background noise. Following Yagi \& Fukahata (2011), we derive the data covariance matrix of $\boldsymbol{d}$ from eq. (12) and represent the stochastic model that relates the data vector $\boldsymbol{d}$ for all stations by the model parameters $\boldsymbol{a}$.

As prior constraints, we use the smoothing constraint on each potency-rate areal-density function $\dot{D}_{q}$ in space and time, represented as,

$$
\begin{aligned}
\nabla^{2} \dot{D}_{q}(t, \xi)+e_{s} & =0, \\
\frac{\partial^{2}}{\partial t^{2}} \dot{D}_{q}(t, \xi)+e_{t} & =0 .
\end{aligned}
$$

As shown in eq (13), we apply the smoothing constraint to the instantaneous spatial distribution of potency-rate areal-density function $\dot{D}_{q}$ in space and time, which makes solutions more stable than the smoothing constraint only on the total spatial distribution (e.g. Ide et al. 1996; Ji et al. 2002).

We can rewrite eqs (13) and (14) in vector form as,

$$
\boldsymbol{S}_{1} \boldsymbol{a}+\boldsymbol{e}_{s}=\mathbf{0}
$$


Table 1. Near-source velocity model (from Avouac et al. 2014) used for calculating Green's functions.

\begin{tabular}{cccc}
$\begin{array}{c}\mathrm{V}_{\mathrm{P}} \\
(\mathrm{km} / \mathrm{s})\end{array}$ & $\begin{array}{c}\mathrm{V}_{\mathrm{S}} \\
(\mathrm{km} / \mathrm{s})\end{array}$ & $\begin{array}{c}\text { Density } \\
\left(10^{3} \mathrm{~kg} / \mathrm{m}^{3}\right)\end{array}$ & $\begin{array}{c}\text { Thickness } \\
(\mathrm{km})\end{array}$ \\
\hline 5.44 & 3.00 & 2.50 & 4.00 \\
6.25 & 3.45 & 2.60 & 12.00 \\
6.53 & 3.60 & 2.70 & 14.00 \\
6.80 & 3.90 & 2.90 & 12.00 \\
7.50 & 4.30 & 2.90 & 3.00 \\
8.11 & 4.49 & 3.30 & 0.00
\end{tabular}

$$
S_{2} a+e_{t}=\mathbf{0}
$$

where $S_{1}$ and $S_{2}$ are $M \times M$ dimensional matrices. We combine these two prior constraints into a single probability-density function, following the method of Fukahata et al. (2003, 2004).

The remaining formulation process, which is conducted following Yagi \& Fukahata (2011), determines the unknown scaling parameters of the modelling error, background noise, and prior constraints on the basis of Akaike's Bayesian Information Criterion (ABIC; Akaike 1980; Yabuki \& Matsu'ura 1992) and iteratively estimates model parameter vectors. As shown by Fukuda \& Johnson (2008), a problem of over-smoothing and under-smoothing can be avoided in our inversion scheme that adopts the ABIC without the non-negative constraint.

In the following sections, we use "potency-rate density" and "potency density" instead of "potencyrate areal density" and "potency areal density" for simplicity.

\section{APPLICATION}

\subsection{Balochistan earthquake}

To test the formulation developed in this study, we applied it to the 2013 Balochistan, Pakistan, earthquake. The epicentre $\left(26.951^{\circ} \mathrm{N}, 65.501^{\circ} \mathrm{E}\right)$ determined by the U.S. Geological Survey, National Earthquake Information Center (USGS NEIC; https://earthquake.usgs.gov/earthquakes/eventpage/usb000jyiv, last accessed 19 November 2018) was in the eastern part of the Makran accretionary wedge in the south-western Pakistan. In the eastern part of the Makran accretionary wedge, the Arabia plate is subducting under the Eurasia plate at a rate of $\sim 40 \mathrm{~mm} / \mathrm{yr}$ in the southern part of Makran accretionary wedge and the eastern side of the Makran accretionary wedge adjoins the India plate, which is converging northwards towards the Eurasia plate at a rate of $\sim 40 \mathrm{~mm} / \mathrm{yr}$ (DeMets et al. 2010) (Fig. 2a). Analy- 
(a)

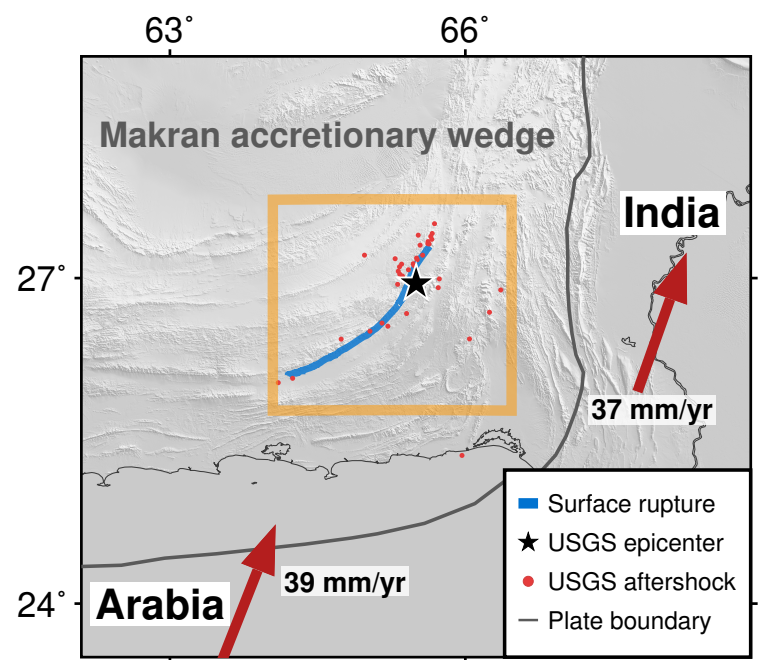

(c) (b)

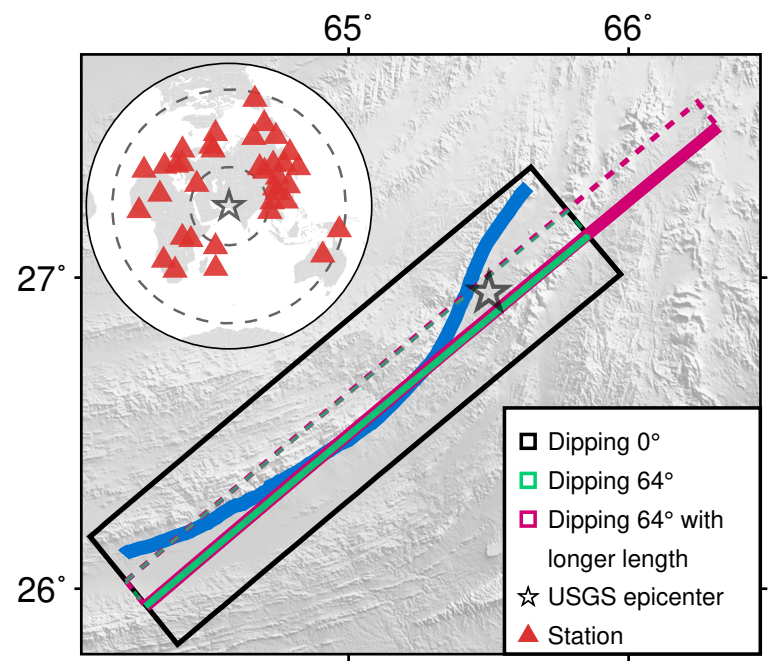

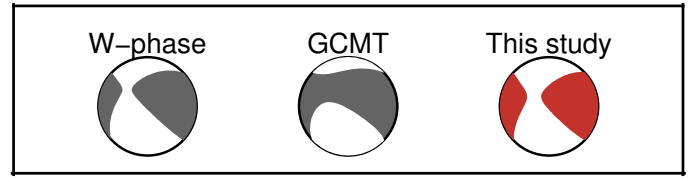

Figure 2. Summary of the tectonic setting and the surface-rupture trace of the 2013 Balochistan earthquake, the model plane settings, and the moment tensor solutions from USGS NEIC, GCMT, and this study. (a) Surface rupture trace (blue line) derived from Zinke et al. (2014). Red dots are aftershocks with $M_{\mathrm{W}} \geq 3$ occurring within 1 week of the mainshock (USGS NEIC; https://earthquake.usgs.gov/earthquakes, last accessed 19 November 2018). Arrows indicate the relative motions of the Arabia and India plates against the Eurasia plate by using the UNAVCO (https://www.unavco.org) plate motion calculator, adopting the MORVEL model (DeMets et al. 2010). The orange rectangle denotes the area shown in Fig. 2(b). Topography was drawn by using 2010 Global Multi-resolution Terrain Elevation Data 7.5 arcsecond median elevations (GMTED; https://topotools.cr.usgs.gov/gmted_viewer/) (Danielson \& Gesch 2011) and the intensity of shade was derived from the directional derivative in $45^{\circ}$ azimuthal direction. (b) Model planes used for the analyses of this study. The top of each model fault plane is shown by a bold line, and the dashed liens outline the dipping model planes. The star denotes the initial rupture point. The blue line represents the surface rupture trace measured by Zinke et al. (2014). The inset map shows the distribution of stations (red triangles) around the epicentre (star) in an azimuthal equidistant projection. The dotted circles show the teleseismic distances at $30^{\circ}$ and $90^{\circ}$. Topography was drawn by using GMTED and the intensity of shade was derived from the directional derivative in $45^{\circ}$ azimuthal direction. (c) Moment tensor solutions. The grey beach balls show the $W$-phase CMT solution provided by USGS (https://earthquake.usgs.gov/earthquakes/eventpage/usb000jyiv/momenttensor, last accessed 19 November 2018) and the GCMT solution from the Global CMT Catalog Search (http://www.globalcmt.org/CMTsearch.html, last accessed 19 November 2018). The red beach ball represents the total moment tensor estimated by this study for a model plane dipping $0^{\circ}$. 
ses of optical satellite images (Avouac et al. 2014; Jolivet et al. 2014; Zinke et al. 2014) and of interferometric synthetic aperture radar (InSAR) data (Barnhart et al. 2014) show a curved surface rupture pattern for the Balochistan earthquake, which is consistent with the arcuate topographic features around the epicentre. The global centroid moment tensor (GCMT; http://www.globalcmt.org/CMTsearch.html, last accessed 19 November 2018) solution and the $W$-phase moment tensor solution determined by USGS (https://earthquake.usgs.gov/earthquakes/eventpage/usb000jyiv, last accessed 19 November 2018) suggest that the Balochistan earthquake was a left-lateral strike-slip earthquake (Fig. 2c). The spatiotemporal distributions of high-frequency radiation sources tracked by back-projection techniques show mostly unilateral rupture propagation towards the south-west from the epicentre (Avouac et al. 2014). The possibly curved and complex fault geometry of the Balochistan earthquake makes construction of a reliable finite-fault model problematic, because use of a simplified fault geometry such as a single planar model or even a configuration of multiple rectangles would cause significant modelling errors as we reviewed in the Introduction and as we discuss further in Section 4.3. Thus, the 2013 Balochistan earthquake provides us an opportunity to test whether our method can extract a complex fault geometry by using the finite-fault inversion framework developed in this study.

\subsection{Data processing and model setting}

The waveform data were downloaded from the Incorporated Research Institutions for Seismology Data Management Center (IRIS-DMC). We selected 36 vertical components of globally observed teleseismic $P$ waveforms, ensuring a high signal-to-noise ratio and a good azimuthal distribution (Fig. $2 b$ ). We manually picked the first motion of the teleseismic $P$ waveforms, removed the seismograph response from the original waveforms to convert into velocity waveforms, and then re-sampled the waveform data at 0.8 -s intervals. Theoretical Green's functions were calculated following Kikuchi \& Kanamori (1991) at 0.1-s intervals, and the attenuation time constant $t^{*}$ for the $P$ wave was taken to be $1.0 \mathrm{~s}$. We used the one-dimensional near-source velocity structure (Table 1) used in Avouac et al. (2014) to calculate the theoretical Green's functions. We do not apply any filter to both the observed waveforms and the theoretical Green's functions. We set a single, flat-model plane, $200 \mathrm{~km}$ long and $45 \mathrm{~km}$ wide, with a strike of $230^{\circ}$ and a dip of $0^{\circ}$ (Fig. 2b) that entirely covered the possible surface rupture area inferred by Zinke et al. (2014). As described in Section 2, our inversion method enables us to estimate the spatiotemporal distribution of potency-rate density. Hence, the strike and dip angles of the assumed model plane are independent of the focal parameters on each space knot that we solve. We horizontally placed the model plane at $7.5 \mathrm{~km}$ depth, which minimized the ABIC value in our test of different hypocentral depth configurations. The model plane was expanded into bilinear B-spline functions with an interval of $5 \mathrm{~km}$ and adopted the epicentral location of $26.951^{\circ} \mathrm{N}, 65.501^{\circ} \mathrm{E}$ for the 
initial-rupture point. The potency-rate-density function at each source knot was represented as a linear combination of B-spline functions with an interval of $0.8 \mathrm{~s}$, assuming a total duration of $31 \mathrm{~s}$ in order to flexibly capture the variation of rupture behaviours. We also assumed the potency-rate density to be zero from $60 \mathrm{~s}$ after the initiation of rupture on the basis of the estimated source-time function in Avouac et al. (2014) and Barnhart et al. (2014). We assumed the maximum rupture-front velocity at to be $4 \mathrm{~km} / \mathrm{s}$, taking into account the possibility of supershear rupture reported by Avouac et al. (2014).

\subsection{Results}

We obtained the distribution of potency-density tensors by integrating the potency-rate-density function for each basis component of potency tensor with respect to time at each space knot (Fig. 3). We represent the potency density at each space knot as an average of absolute value of eigenvalues for $T$ - and $P$ - axes of a diagonalised potency-density tensor at each space knot. The potency density is larger around the epicentre and extend to south-west from the epicentre about $150 \mathrm{~km}$. It is difficult to uniquely determine fault parameters from a focal mechanism solution by our method alone. Here, we take the fault plane whose strike was in the range between $180^{\circ}$ and $270^{\circ}$, based on the mapping of the surface rupture (e.g. Zinke et al. 2014). The potency-density tensors show strike-slip faulting with a strike of $216^{\circ}$ and a dip of $77^{\circ}$ around the epicentre (Fig. 3). We can also see strike-slip faulting with a strike of $243^{\circ}$ and a dip of $45^{\circ}$ around $80 \mathrm{~km}$ south-west from the epicentre, and reverse or oblique-slip faulting with a strike of $244^{\circ}$ and a dip of $53^{\circ}$ around $140 \mathrm{~km}$ south-west from the epicentre (Fig. 3). The total moment tensor, which was obtained by taking a spatial integration of the potency-density tensors shown in Fig. 3, shows strike-slip faulting with a strike of $226^{\circ}$ and a dip of $61^{\circ}$, and it includes $8 \%$ of the non-double-couple components (Fig. 2c). The total released seismic moment was $7.53 \times$ $10^{20} \mathrm{Nm}\left(M_{\mathrm{W}} 7.8\right)$, comparable to the GCMT solution of $5.59 \times 10^{20} \mathrm{Nm}\left(M_{\mathrm{W}} 7.8\right)$. The source-time function, obtained by calculating the seismic moment at each time step, has a major peak at around 17 $\mathrm{s}$ and three minor peaks at around 29 s, 43 s and 53 s (Fig. 3 and Supporting Information Fig. S14).

To clearly visualize the spatiotemporal variation of focal mechanisms, we showed a potency-density tensor on its centroid location within 10-s time window by taking the spatial and temporal integration of the potency-rate density along the model plane (Fig. 4). In this representation, the centroid location propagates unilaterally towards the south-west from the epicentre, with a longer centroid migration distance in the period from 20 to $50 \mathrm{~s}$ compared with that before $20 \mathrm{~s}$ or after $50 \mathrm{~s}$. The potencydensity tensor in each time window shows a successive transition during 0 to $60 \mathrm{~s}$ from strike-slip faulting with strike and dip angles of $205^{\circ}$ and $68^{\circ}$, respectively, to oblique-slip faulting with strike and dip angles of $241^{\circ}$ and $39^{\circ}$, respectively, with clockwise north-to-south rotation of the strike angle (Fig. 4). This transition of the focal mechanism in time is consistent with what can be seen in the static, 
spatial variation of the distribution of potency-density tensors (Fig. 3). This consistency can be seen even if we took 3-s time window instead of 10-s time window (Supporting Information Fig. S13).

We also show the temporal change of focal mechanisms at all space knots by integrating the potencyrate-density function with respect to time in each time window and by plotting the strike and dip angles in the strike angle range between $180^{\circ}$ and $270^{\circ}$ (Fig. 5a). As can be seen in the histogram snapshots (Fig. 5a), the strike angle changes successively from $200^{\circ}$ to $240^{\circ}$ during 0 to $50 \mathrm{~s}$, showing the clockwise rotation of the fault plane during rupture evolution. The dip angles are steep, around $80^{\circ}$, during 0 to $20 \mathrm{~s}$, and then become shallow, around $60^{\circ}$, during 20 to $50 \mathrm{~s}$. Note that during the fast migration of the centroid locations from 20 to $50 \mathrm{~s}$ (Fig. 4), the distribution of dip angles shows more scatter than the distribution during 0 to $20 \mathrm{~s}$. During 50 to $60 \mathrm{~s}$, the distributions of strike angle and dip angle are scattered. We also plotted the strike and dip angles of the two nodal planes for all space knots without taking a certain range of strike angles for all time windows (Fig. 5b). Two strike angle modes at around $130^{\circ}$ and $230^{\circ}$ (Fig. 5b) reflect the two possible conjugated fault planes.

\section{DISCUSSION}

\subsection{Rupture propagation and fault geometry}

The unilateral rupture propagation towards the south-west from the epicentre (Fig. 4) is consistent with the spatiotemporal distribution of high-frequency radiation sources tracked by the back-projection technique (Avouac et al. 2014). The estimated average centroid location migration velocity during 20 to $50 \mathrm{~s}$ (Fig. 4) was $3.8 \mathrm{~km} / \mathrm{s}$, which is faster than the local shear-wave velocity at the depth of the model plane that we placed (Table. 1). Although we can not directly compare the migration velocity of the centroid location and the rupture front velocity inferred by the back-projection (Avouac et al. 2014), the period of 20 to $50 \mathrm{~s}$, when the centroid migration velocity exceeds the shear-wave velocity, is consistent with the timing of a rupture velocity exceeding the local shear-wave velocity observed by Avouac et al. (2014).

The trend of the surface-rupture trace measured by Zinke et al. (2014) has an azimuthal angle of $200^{\circ}$ around the epicentre, $230^{\circ}$ around $80 \mathrm{~km}$ south-west of the epicentre, and $240^{\circ}$ around $140 \mathrm{~km}$ south-west of the epicentre; these angles are in agreement with the strike angles of the total potencydensity tensor distribution (Fig. 3) and the strike angle of the potency-density tensor in each $10 \mathrm{~s}$ window (Fig. 4). The estimated shallow-dipping fault in the south-western part of the source region (Fig. 3), which can also be seen in the temporal evolution of the rupture (Figs. 4 and 5), may be related to an active thrust fault in the Makran accretionary wedge (Haghipour et al. 2012). The CLVD component of potency-density tensor at individual source knots is not apparently significant, implying that 


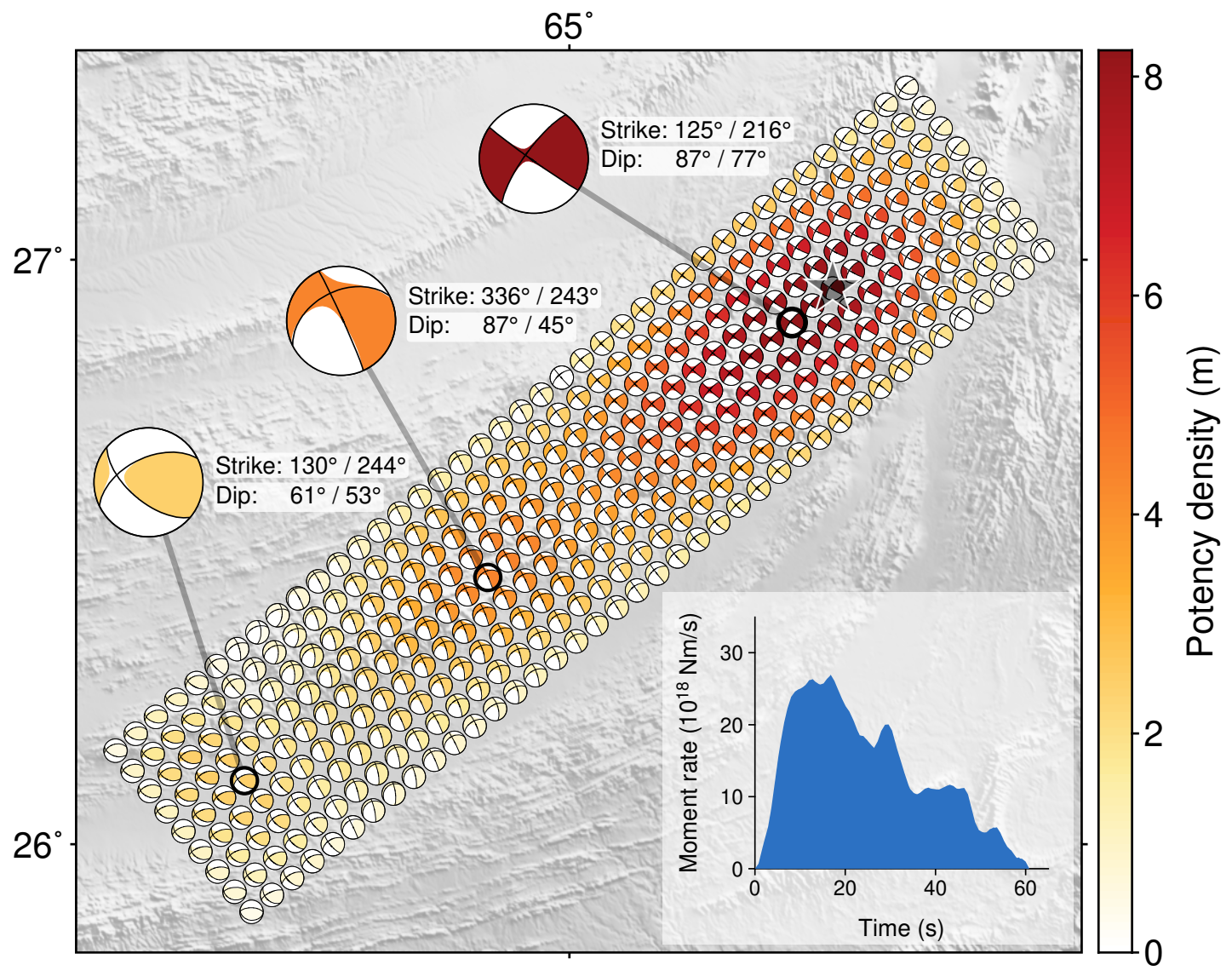

Figure 3. Spatial distribution of the potency-density tensors and moment-rate function (inset). The small beach ball shows the focal mechanism at each source knot, plotted using a lower-hemisphere stereographic projection. The star denotes the epicentre. The beach ball colour shows the potency density. Some beach balls (with black outline) have been selected and enlarged to highlight the spatial variation of the focal mechanism. Strike and dip angles are shown at right side of the enlarged beach balls.

teleseismic $P$ waves can be used to constrain a CLVD component of a shallow strike-slip earthquake if station distribution ensures a good azimuthal coverage. (Fig. 3).

The results of the analysis show that we can estimate the direction of rupture propagation and the curved fault geometry, both of which are consistent with the back-projection analysis and optical satellite images, simply by distributing the source knots along a single model plane dipping $0^{\circ}$. The rupture extent of the Balochistan earthquake seems to be distributed mainly at depths shallower than $15 \mathrm{~km}$ (e.g. Avouac et al. 2014; Barnhart et al. 2014) and uncertainty in Green's function is taken into account, which may account for the realistic results obtained by using a model plane dipping $0^{\circ}$. It should also be noted that when we apply a method that is the same as our new method but neglecting uncertainty in Green's function, the obtained source model shows the focal mechanisms whose strike angles are inconsistent with the trend of both the north-east and the south-west sides of the surface- 


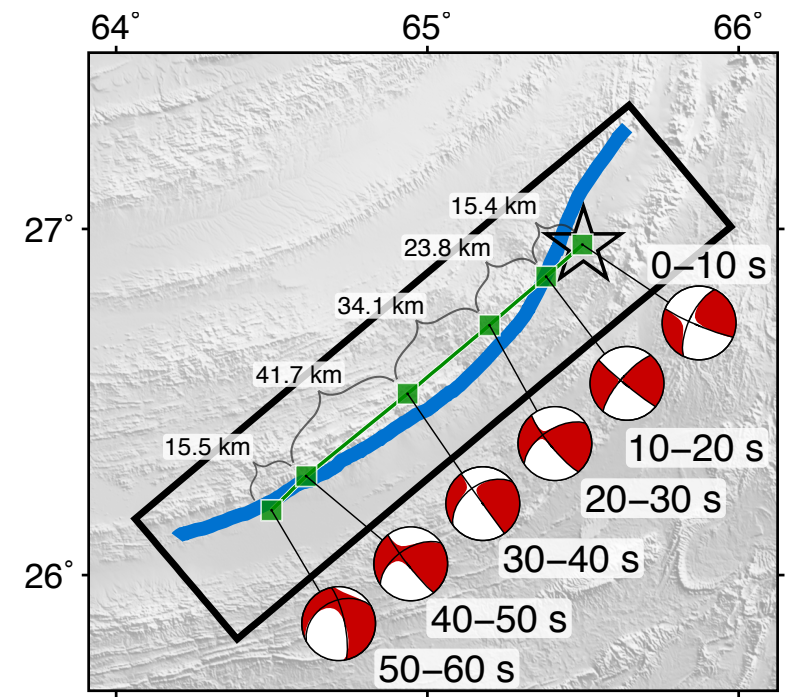

Figure 4. The evolution of the centroid of the potency-rate-density tensors. The centroid locations (green squares) of the potency-rate density and its potency-density tensor is shown at each time window, along with the distance between the neighbouring centroid locations and the corresponding time window for estimation of the centroid location. The blue line represents the surface-rupture trace measured by Zinke et al. (2014). The rectangle outlines the model plane. The star denotes the epicentre.

rupture trace measured by Zinke et al. (2014) (Supporting Information Fig. S12). When we analyze an earthquake with a wide rupture extent in depth, such as a subduction zone earthquake, it is better to adopt a plausible dip angle of a model plane.

We evaluated the robustness of our new method by performing the synthetic tests, where 4 kinds of input source models were prepared; those were, the source model of the 2013 Balochistan earthquake, a simple reverse faulting model, a source model including drastic change of focal mechanism, and a strike-slip faulting model within a bending fault (Supporting Information Text S1). The results show that our new method can reproduce the drastic change of focal mechanism and the change of strike angle of the bending strike-slip fault during the rupture propagation without adhoc assumptions of fault geometry (Supporting Information Figs. S1-S9).

The 2.5 times larger number of model parameters in our new inversion scheme than the conventional one means a freedom from the constraint on shear-slip direction that is one of prior constraints implicitly imposed in conventional methods. Solutions obtained by our new method tend to be spatiotemporally smooth, and inferred focal mechanisms contain CLVD components even if a true source mechanism is a pure double couple, which can be seen in the synthetic tests (Supporting Information Figs. S3a, b and S4).

The multiple-point-source inversions (e.g. Kikuchi \& Kanamori 1991; Duputel et al. 2012) can estimate a single focal mechanism for each subevent with a simplified source-time function, but they 
(a)
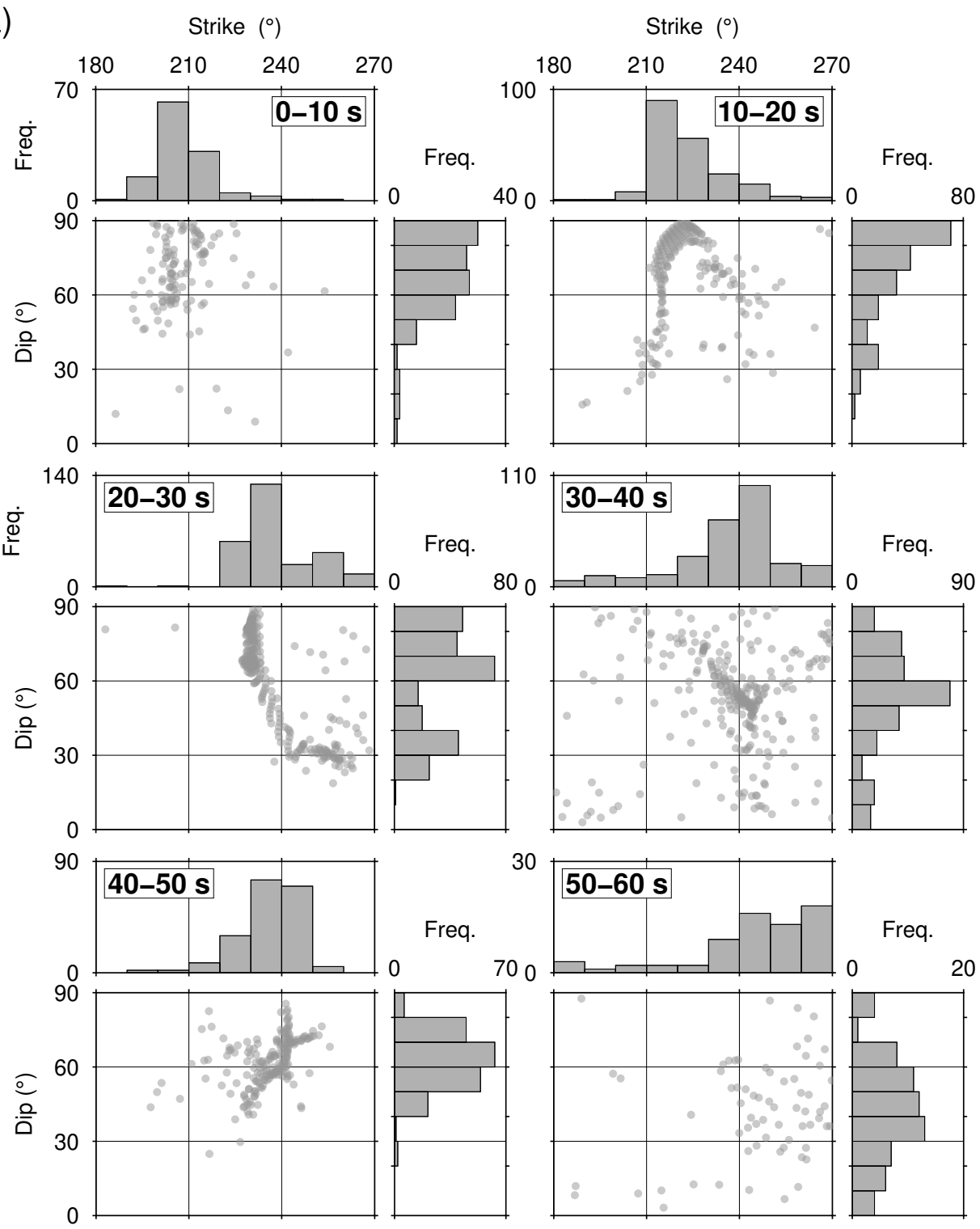

Freq.
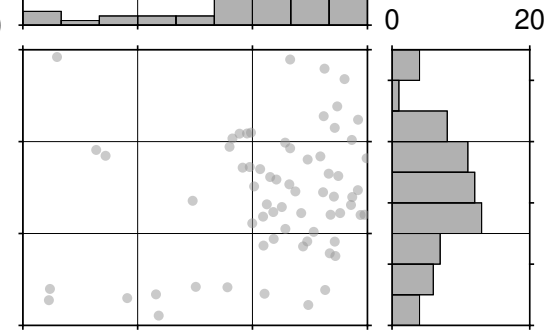

(b)

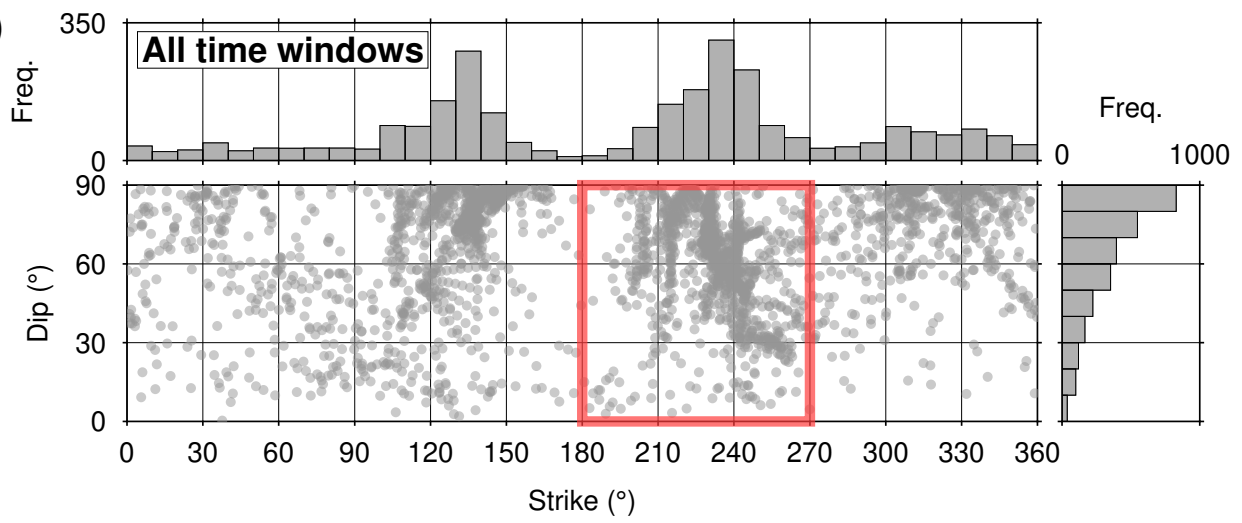

Figure 5. Configurations of strike and dip angles of all source knots in (a) each time window and (b) all time windows. The histograms group the angles in $10^{\circ}$ bins. The red rectangle in (b) denotes the range of strike and dip angles shown in (a). 
(a)

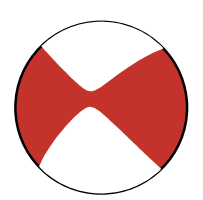

(b)

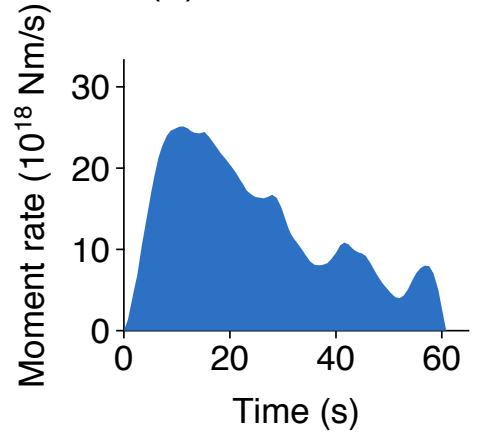

(c)

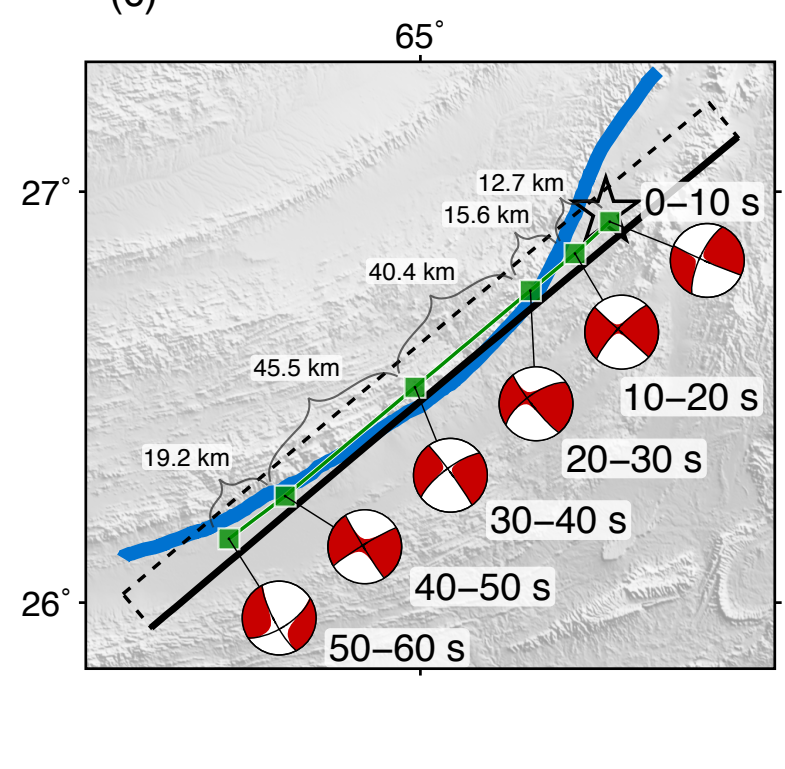

Figure 6. (a) Total moment tensor, (b) moment-rate function, and (c) evolution of the centroid of the potencyrate-density tensors obtained by using the model plane dipping $64^{\circ}$. The star denotes the USGS epicentre. The dashed line outlines the model fault, and the bold black line shows the top of the model fault, respectively. The green squares and beach balls represent the centroid location and total potency-density tensor, respectively, each time window, along with the distance between neighbouring centroid locations and the corresponding time window for estimating the centroid location.

can not resolve detailed rupture propagation and a change of focal mechanism within a subevent. A focal mechanism within a subevent should vary in space and time, and the source-time function should be able to represent azimuth-dependent shape and duration, reflecting the directivity effects. Therefore, applying the multiple-point-source inversion is inappropriate for estimating detailed rupture propagation between subevents and resolving smoothly curved fault geometry, such as those of the 2013 Balochistan earthquake. Comparing with the multiple-point-source inversions, it is relatively difficult for our method to infer an abrupt change of focal mechanism because of the spatiotemporal smoothing constraints, however, our new finite-fault inversion framework can spatiotemporally resolve both the detailed rupture evolution and variation of the focal mechanism without non-negative slip constraint, and this high flexibility is due to the fact that uncertainty in Green's functions is explicitly taken into account.

\subsection{Effects of a model plane geometry}

For simplicity, we represented the spatiotemporal potency-rate-density distribution in a two-dimensional model space by assuming eq. (3), which represents the insensitivity of Green's function to a slight 


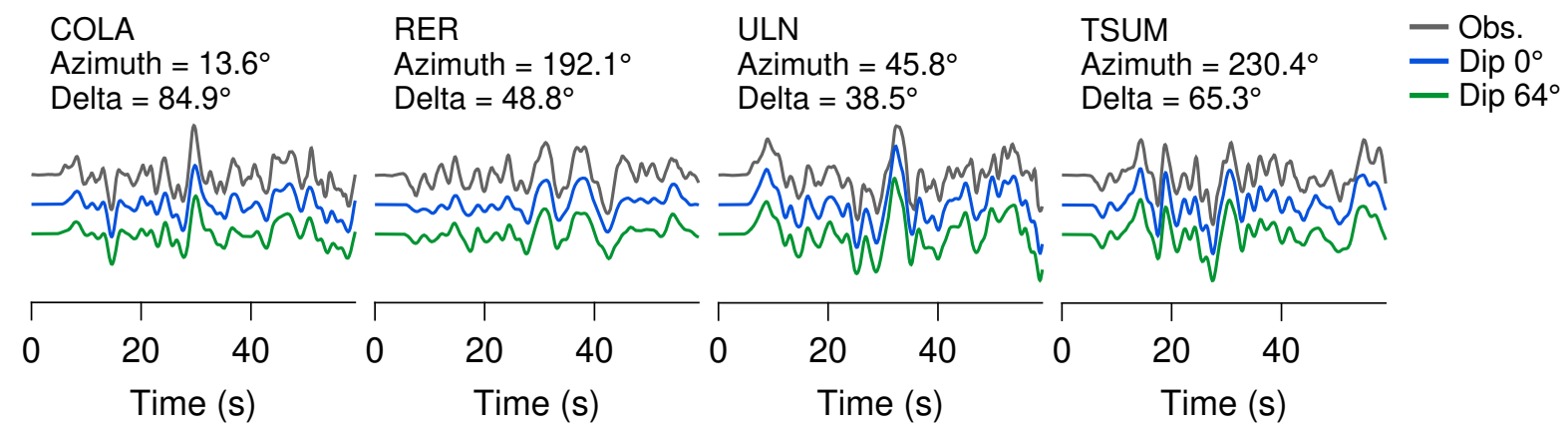

Figure 7. Fitting of waveforms between observed (top grey line) and synthetic waveforms for the model planes dipping $0^{\circ}$ (middle blue line) and dipping 64 (bottom green line). The waveforms are plotted with a sampling interval of $0.05 \mathrm{~s}$. The stations were selected to highlight the difference in the results of the fittings. Station code, azimuth, and epicentral distance are shown above the traces.

change of source location, and then neglected modelling errors originated from uncertainty in the model plane geometry. In this section, we evaluated the effects of the approximation of Green's function in eq. (3) and the robustness of our new method by changing the model plane geometry.

We changed the dip angle of the model plane from $0^{\circ}$ to $64^{\circ}$, the average dip angle of model planes used in the finite-fault inversion analysis conducted by USGS NEIC (https://earthquake.usgs.gov/earthquakes/eventpage/ last accessed 19 November 2018), used the hypocentre determined by USGS NEIC as an initial rupture point, and adopted a model plane with a length of $200 \mathrm{~km}$ and a width of $25 \mathrm{~km}$ (Fig. 2b).

The total moment tensor shows strike-slip faulting with the more realistic fault plane having a $226^{\circ}$ strike angle and a $77^{\circ}$ dip angle (Fig. 6a); this dip angle is steeper than that of the more realistic fault plane of the total moment tensor obtained by the analysis using a model plane dipping $0^{\circ}$ (Fig. 2c). The total released seismic moment was $7.00 \times 10^{20} \mathrm{Nm}\left(M_{\mathrm{W}} 7.8\right)$, which is comparable to the analysis result obtained with the model plane dipping $0^{\circ}$. The source-time function has a major peak at around $11 \mathrm{~s}$ and three minor peaks at around $28 \mathrm{~s}, 42 \mathrm{~s}$ and $57 \mathrm{~s}$ (Fig. $6 \mathrm{~b}$ and Supporting Information Fig. S14). Timings of the peaks in the source-time function are shifted in time within 1-5 s earlier than those of the previous result, which is originated from travel time difference due to the different model plane geometries, but the number and relative amplitudes of the peaks are comparable to the previous result (Fig. 3 and Supporting Information Fig. S14). The focal mechanisms during 0 to 30 s show overall similarity of the potency-density tensors between the model plane dipping $0^{\circ}$ and that dipping $64^{\circ}$ (Figs. 4 and 6). The average centroid location migration velocity during 20 to $50 \mathrm{~s}$ increases to 4.3 $\mathrm{km} / \mathrm{s}$ (Fig. 6), which is consistent with the previous result (Fig. 4). The strike angles of the potencydensity tensors in the $10 \mathrm{~s}$ windows rotate clockwise as the rupture propagates towards the south-west from the epicentre until $50 \mathrm{~s}$.

Although the rupture propagating unilaterally south-westward and the transition of focal mecha- 
nism showing the clockwise north-to-south rotation of the strike angle are consistent with the previous results obtained with the model plane dipping $0^{\circ}$, the potency-density tensors during 30 to $60 \mathrm{~s} \mathrm{(Fig.}$ 6c) show steeper dip angles than those obtained by the analysis adopting with a model plane dipping $0^{\circ}$, and this difference in dip angle seems to become larger as the rupture evolves. The waveform fitting between the observed and synthetic waveforms is comparable between the two analyses (Fig. 7 and Supporting Information Fig. S10), but the variance is 0.04 larger in the analysis with the model plane dipping $64^{\circ}$. Because the dip angle of the model plane prescribes the source spatial location and the model plane dipping $0^{\circ}$ horizontally covers the possible source region more broadly than that dipping $64^{\circ}$ (Fig. 2b), modelling error due to inadequate assumption of the model-source location may be smaller for a model plane dipping $0^{\circ}$.

\subsection{Bias due to limited number of basis double-couple components}

To evaluate how the conventional inversion scheme suffers from the modelling error of the fault geometry, we applied the conventional method (Fig. 1b) to the Balochistan earthquake by assuming a flat model plane with a length of $260 \mathrm{~km}$ (extending the model plane $60 \mathrm{~km}$ farther north-eastward compared with our previous two analyses), and a width of $25 \mathrm{~km}$, a strike of $230^{\circ}$, and a dip of $64^{\circ}$ (Fig. $2 b)$. In our application of the conventional method, we employed the formulation of Yagi \& Fukahata (2011), introducing the uncertainty in Green's functions into the data covariance matrix in the same way as in the method developed in this study, but adopting only the two basis components of potency tensor.

With the conventional inversion scheme, the resultant seismic moment was $7.27 \times 10^{20} \mathrm{Nm}\left(M_{\mathrm{W}}\right.$ 7.8), which is comparable to that obtained by the new method developed in this study $\left(6.43 \times 10^{20}\right.$ $\left.\mathrm{Nm}, M_{\mathrm{W}} 7.8\right)$. However, the rupture propagation direction was opposite between the conventional and the new inversion schemes (Fig. 8). The conventional result showed the rupture propagating almost unilaterally north-eastward from the epicentre (Fig. 8b), with the dominant rupture area distributed in the area north-east of the source region (Fig. 8d). This north-eastward rupture propagation is unlikely to be realistic because, as shown in the previous sections, both the surface rupture mapped by the satellite image analyses and the back-projection result suggest that the rupture propagated toward south-west from the epicentre (e.g. Avouac et al. 2014). However, it should be noted that the variance of the waveform fittings obtained with the new method was only 0.04 less than that obtained with the conventional method, although the certain phases of the observed waveforms were not well reproduced at some stations in the conventional inversion scheme (Fig. 8e and Supporting Information Fig. S11). Even though the difference of the variance between the two methods seems small, the conventional method using only two basis components of potency tensor could not reproduce the realistic direc- 
tion of rupture propagation, which was independently inferred from other data and analyses. We thus conclude that, even if we introduce the uncertainty in Green's functions into the covariance matrix, a simplified assumption of the fault geometry that limits the flexibility of slip directions may distort the solution (Fig. 8) and thereby lead to inappropriate interpretations of the source process. When we analyze seismic data with little information on fault geometry of an earthquake, such a single wide model plane, which may be inconsistent with the true one, is commonly adopted for constructing a preliminary source model. In this case, however, inappropriate models may be obtained due to modelling errors originated from uncertainty in fault geometry. Our new method enables us to mitigate such a problem, and to construct a realistic source model without detailed information about the fault geometry. 
This study

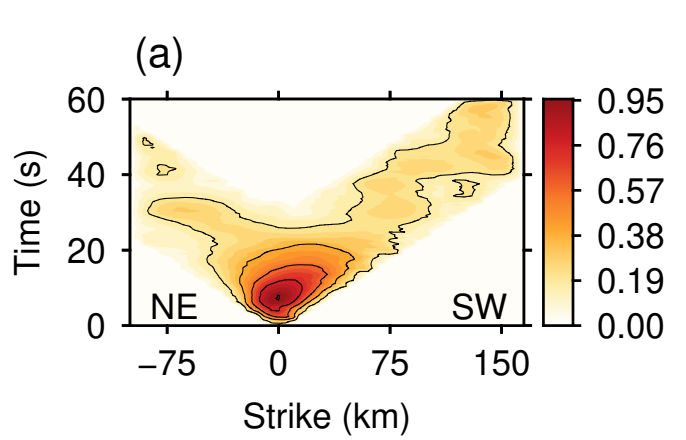

(c)

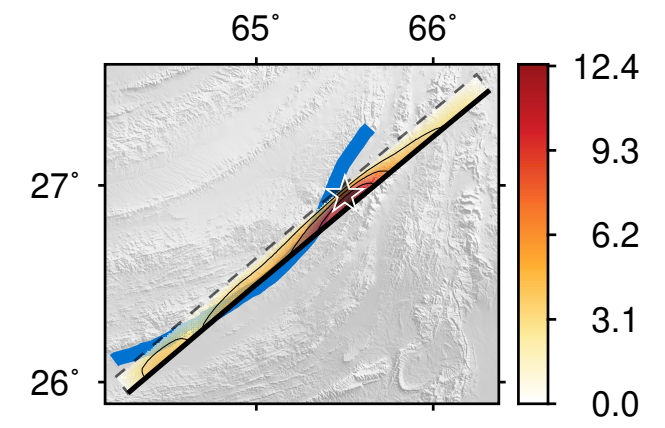

\section{Conventional}

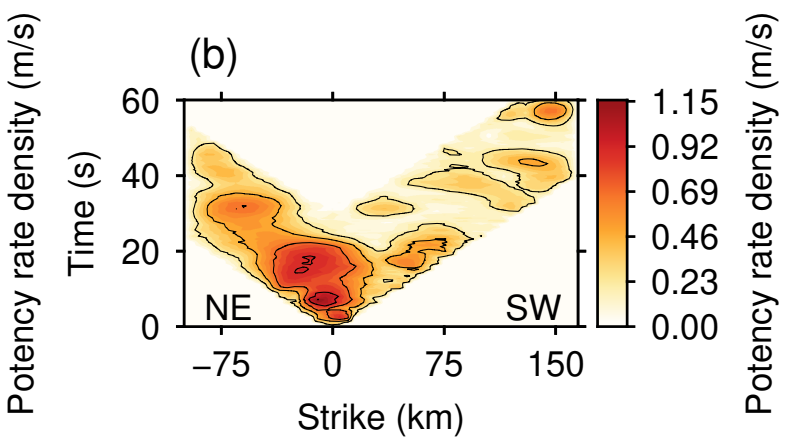

(d)

(e)

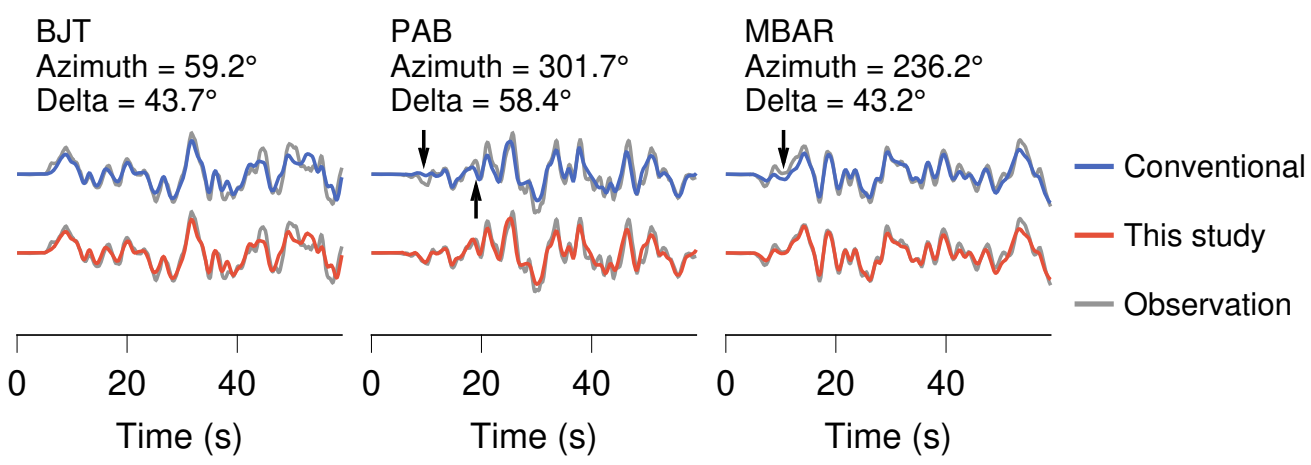

Figure 8. The difference between the models obtained by using the formulation developed in this study and the one used by Yagi \& Fukahata (2011). (a, b) Time evolution of potency-rate density along the strike direction and (c, d) total potency-density distribution obtained with the new and conventional formulation, respectively. The star denotes the USGS epicentre. The dashed line outlines the model fault, and the bold black line shows the top of the model fault. Contour intervals in (a), (b), (c) and (d) are $0.19 \mathrm{~m} / \mathrm{s}, 0.22 \mathrm{~m} / \mathrm{s}, 3.1 \mathrm{~m}$ and $3.7 \mathrm{~m}$, respectively. (e) Comparison of waveform fitting at selected stations. The waveforms are plotted with a sampling interval of $0.05 \mathrm{~s}$. The station code, azimuth, and epicentral distance are shown above the traces. Arrows point out the phases where the observed waveform was not well reproduced by the conventional method. 


\section{CONCLUSION}

In this study, we proposed a new method of finite-fault inversion of teleseismic $P$ waveforms in which shear slip along an assumed flat plane is represented by a superposition of five basis components of potency-density tensor. Because we extended the formulation of Yagi \& Fukahata (2011), our method makes it possible not only to estimate a fault geometry but also to mitigate effects of uncertainties of Green's function and fault geometry, which are two major sources of modelling errors. By applying our method to the 2013 Balochistan earthquake, we confirmed that the estimated direction of rupture propagation and the spatiotemporal distribution of focal mechanisms were consistent with those independently inferred from the back-projection result and the optical satellite images. This result suggests that our method is applicable to an earthquake that involves complex fault geometry and makes it possible to extract the information of the fault geometry, which contributes to a reliable source modelling.

\section{ACKNOWLEDGMENTS}

We greatly appreciate the editor Martin Mai, the reviewer Chen Ji and the anonymous reviewer for their thorough and constructive reviews that significantly improved our manuscript. This work was supported by the Japan Society for the Promotion of Science (JSPS) KAKENHI Grant-in-Aid for Scientific Research (JP16K05529, JP16H01842, JP16K05539) and JSPS KAKENHI Grant-inAid for Scientific Research on Innovative Areas (JP16H06477, JP18H05447). The authors thank Amato Kasahara, Hisahiko Kubo, Jean-Philippe Avouac, Keita Kayano, Naotaka Chikasada, and Takanori Matsuzawa for their valuable comments and suggestions. Teleseismic waveforms from the networks, GEOSCOPE, Hong Kong Seismographic Network, Global Telemetered Seismograph Network (USAF/USGS), New China Digital Seismograph Network, Global Seismograph Network (GSNIRIS/IDA), and Global Seismograph Network (GSN-IRIS/USGS), were downloaded from the IRISDMC website (https://ds.iris.edu/ds/nodes/dmc/). All the figures were created with Generic Mapping Tools (Wessel \& Smith 1998).

\section{REFERENCES}

Akaike, H., 1980. Likelihood and the Bayes procedure, Trabajos de Estadistica Y de Investigacion Operativa, 31(1), 143-166.

Aki, K., 1979. Characterization of Barriers on an Earthquake Fault, Journal of Geophysical Research: Solid Earth, 84(9), 6140-6148.

Ampuero, J. P. \& Dahlen, F. A., 2005. Ambiguity of the moment tensor, Bulletin of the Seismological Society of America, 95(2), 390-400. 
Avouac, J. P., Ayoub, F., Wei, S., Ampuero, J. P., Meng, L., Leprince, S., Jolivet, R., Duputel, Z., \& Helmberger, D., 2014. The 2013, Mw 7.7 Balochistan earthquake, energetic strike-slip reactivation of a thrust fault, Earth and Planetary Science Letters, 391, 128-134.

Backus, G. \& Mulcahy, M., 1976. Moment Tensors and other Phenomenological Descriptions of Seismic Sources-I. Continuous Displacements, Geophysical Journal International, 46(2), 341-361.

Barnhart, W. D., Hayes, G. P., Briggs, R. W., Gold, R. D., \& Bilham, R., 2014. Ball-and-socket tectonic rotation during the 2013 Mw7.7 Balochistan earthquake, Earth and Planetary Science Letters, 403, 210-216.

Beresnev, I. A., 2003. Uncertainties in finite-fault slip inversions: To what extent to believe? (A critical review), Bulletin of the Seismological Society of America, 93(6), 2445-2458.

Bodin, T., Sambridge, M., \& Gallagher, K., 2009. A self-parametrizing partition model approach to tomographic inverse problems, Inverse Problems, 25(5).

Chen, Y., Wen, L., \& Ji, C., 2014. A cascading failure during the 24 May 2013 great Okhotsk deep earthquake, Journal of Geophysical Research: Solid Earth, pp. 3035-3049.

Danielson, J. J. \& Gesch, D. B., 2011. Global multi-resolution terrain elevation data 2010 (GMTED2010), Tech. rep.

DeMets, C., Gordon, R. G., \& Argus, D. F., 2010. Geologically current plate motions, Geophysical Journal International, 181(1), 1-80.

Du, Y., Aydin, A., \& Segall, P., 1992. Comparison of various inversion techniques as applied to the determination of a geophysical deformation model for the 1983 Borah Peak earthquake, Bulletin of the Seismological Society of America, 82(4), 1840-1866.

Duputel, Z. \& Rivera, L., 2017. Long-period analysis of the 2016 Kaikoura earthquake, Physics of the Earth and Planetary Interiors, 265, 62-66.

Duputel, Z., Rivera, L., Kanamori, H., \& Hayes, G., 2012. W phase source inversion for moderate to large earthquakes (1990-2010), Geophysical Journal International, 189(2), 1125-1147.

Duputel, Z., Agram, P. S., Simons, M., Minson, S. E., \& Beck, J. L., 2014. Accounting for prediction uncertainty when inferring subsurface fault slip, Geophysical Journal International, 197(1), 464-482.

Freymueller, J., King, N. E., \& Segall, P., 1994. The Coseismic Slip Distribution of the Landers Earthquake, Bulletin of the Seismological Society of America, 84(3), 646-659.

Fukahata, Y. \& Wright, T. J., 2008. A non-linear geodetic data inversion using ABIC for slip distribution on a fault with an unknown dip angle, Geophysical Journal International, 173(2), 353-364.

Fukahata, Y., Yagi, Y., \& Matsu'ura, M., 2003. Waveform inversion for seismic source processes using ABIC with two sorts of prior constraints: Comparison between proper and improper formulations, Geophysical Research Letters, 30(6), 1-4.

Fukahata, Y., Nishitani, A., \& Matsu' ura, M., 2004. Geodetic data inversion using ABIC to estimate slip history during one earthquake cycle with viscoelastic slip-response functions, Geophysical Journal International, 156(1), 140-153.

Fukuda, J. \& Johnson, K. M., 2008. A fully Bayesian inversion for spatial distribution of fault slip with 
objective smoothing, Bulletin of the Seismological Society of America, 98(3), 1128-1146.

Gombert, B., Duputel, Z., Jolivet, R., Doubre, C., Rivera, L., \& Simons, M., 2018. Revisiting the 1992 Landers earthquake: A Bayesian exploration of co-seismic slip and off-fault damage, Geophysical Journal International, 212(2), 839-852.

Haghipour, N., Burg, J. P., Kober, F., Zeilinger, G., Ivy-Ochs, S., Kubik, P. W., \& Faridi, M., 2012. Rate of crustal shortening and non-Coulomb behaviour of an active accretionary wedge: The folded fluvial terraces in Makran (SE, Iran), Earth and Planetary Science Letters, 355-356, 187-198.

Hartzell, S. H. \& Heaton, T. H., 1983. Inversion of strong ground motion and teleseismic waveform data for the fault rupture history of the 1979 Imperial Valley, California, earthquake, Bulletin of the Seismological Society of America, 73(6), 1553-1583.

Ide, S., Takeo, M., \& Yoshida, Y., 1996. Source Process of the 1995 Kobe Earthquake: Determination of SpatioTemporal Slip Distribution by Bayesian Modeling, Bulletin of the Seismological Society of America, 86(3), 547-566.

Ji, C., Wald, D. J., \& Helmberger, D. V., 2002. Source description of the 1999 Hector Mine, California, earthquake, part I: Wavelet domain inversion theory and resolution analysis, Bulletin of the Seismological Society of America, 92(4), 1192-1207.

Jolivet, R., Duputel, Z., Riel, B., Simons, M., Rivera, L., Minson, S. E., Zhang, H., Aivazis, M. A., Ayoub, F., Leprince, S., Samsonov, S., Motagh, M., \& Fielding, E. J., 2014. The 2013 Mw7.7 Balochistan earthquake: Seismic potential of an accretionary wedge, Bulletin of the Seismological Society of America, 104(2), 10201030 .

Kikuchi, M. \& Kanamori, H., 1991. Inversion of Complex Body Waves-III, Bulletin of the Seismological Society of America, 81(6), 2335-2350.

Mai, P. M., Schorlemmer, D., Page, M., Ampuero, J., Asano, K., Causse, M., Custodio, S., Fan, W., Festa, G., Galis, M., Gallovic, F., Imperatori, W., Käser, M., Malytskyy, D., Okuwaki, R., Pollitz, F., Passone, L., Razafindrakoto, H. N. T., Sekiguchi, H., Song, S. G., Somala, S. N., Thingbaijam, K. K. S., Twardzik, C., van Driel, M., Vyas, J. C., Wang, R., Yagi, Y., \& Zielke, O., 2016. The Earthquake - Source Inversion Validation (SIV) Project, Seismological Research Letters, 87(3), 690-708.

Minson, S. E., Simons, M., \& Beck, J. L., 2013. Bayesian inversion for finite fault earthquake source models I-theory and algorithm, Geophysical Journal International, 194(3), 1701-1726.

Minson, S. E., Murray, J. R., Langbein, J. O., \& Gomberg, J. S., 2014. Real-time inversions for finite fault slip models and rupture geometry based on high-rate GPS data, Journal of Geophysical Research: Solid Earth, 119(4), 3201-3231.

Nocquet, J. M., 2018. Stochastic static fault slip inversion from geodetic data with non-negativity and bound constraints, Geophysical Journal International, 214(1), 366-385.

Okuwaki, R. \& Yagi, Y., 2018. Role of geometric barriers in irregular-rupture evolution during the 2008 Wenchuan earthquake, Geophysical Journal International, 212(3), 1657-1664.

Olson, A. H. \& Apsel, R. J., 1982. Finite faults and inverse theory with applications to the 1979 Imperial 


\section{K. Shimizu, Y. Yagi, R. Okuwaki, and Y. Fukahata}

Valley earthquake, Bulletin of the Seismological Society of America, 72(6), 1969-2001.

Ragon, T., Sladen, A., \& Simons, M., 2018. Accounting for uncertain fault geometry in earthquake source inversions - I : theory and simplified application, Geophysical Journal International, 214, 1174-1190.

Shi, Q., Wei, S., \& Chen, M., 2018. An MCMC multiple point sources inversion scheme and its application to the 2016 Kumamoto Mw 6.2 earthquake, Geophysical Journal International, 215(2), 737-752.

Wessel, P. \& Smith, W. H. F., 1998. New, improved version of generic mapping tools released, Eos, Transactions American Geophysical Union, 79(47), 579.

Yabuki, T. \& Matsu'ura, M., 1992. Geodetic data inversion using a Bayesian information criterion for spatial distribution of fault slip, Geophysical Journal International, 109(2), 363-375.

Yagi, Y. \& Fukahata, Y., 2008. Importance of covariance components in inversion analyses of densely sampled observed data: An application to waveform data inversion for seismic source processes, Geophysical Journal International, 175(1), 215-221.

Yagi, Y. \& Fukahata, Y., 2011. Introduction of uncertainty of Green's function into waveform inversion for seismic source processes, Geophysical Journal International, 186(2), 711-720.

Yagi, Y., Nakao, A., \& Kasahara, A., 2012. Smooth and rapid slip near the Japan Trench during the 2011 Tohoku-oki earthquake revealed by a hybrid back-projection method, Earth and Planetary Science Letters, 355-356, 94-101.

Zhang, Y. \& Wang, R., 2015. Geodetic inversion for source mechanism variations with application to the 2008 Mw7.9 wenchuan earthquake, Geophysical Journal International, 200(3), 1627-1635.

Zinke, R., Hollingsworth, J., \& Dolan, J. F., 2014. Surface slip and off-fault deformation patterns in the 2013 MW7.7 Balochistan, Pakistan earthquake: Implications for controls on the distribution of near-surface coseismic slip, Geochemistry, Geophysics, Geosystems, 15(12), 5034-5050. 


\title{
Supporting Information for "Development of an inversion method to extract information on fault geometry from
}

\section{teleseismic data"}

\author{
Kousuke Shimizu, ${ }^{1}$ Yuji Yagi, ${ }^{2}$ Ryo Okuwaki, ${ }^{2}$ and Yukitoshi Fukahata ${ }^{3}$ \\ ${ }^{1}$ Graduate School of Life and Environmental Sciences, University of Tsukuba, Tsukuba, Ibaraki 305-8572, Japan. \\ ${ }^{2}$ Faculty of Life and Environmental Sciences, University of Tsukuba, Tsukuba, Ibaraki 305-8572, Japan. \\ ${ }^{3}$ Disaster Prevention Research Institute, Kyoto University, Uji, Kyoto 611-0011, Japan.
}

\section{CONTENTS}

Text S1. Synthetic tests.

Figure S1 to Figure S9. Results of synthetic tests.

Figure S10. Waveform fitting at all stations between observed and synthetic waveforms for the model planes dipping $0^{\circ}$ and dipping $64^{\circ}$.

Figure S11. Waveform fitting at all stations between observed and synthetic waveforms for the source models obtained by a conventional method and our method.

Figure S12. Source models where uncertainty of Green's function is neglected and introduced.

Figure S13. Evolution of the centroid of the potency-rate-density tensors.

Figure S14. Source-time functions for the model planes dipping $0^{\circ}$ and $64^{\circ}$. 


\section{Text S1}

We performed numerical simulations for testing the formulation developed in this study. We took $26.951^{\circ} \mathrm{N}$ and $65.501^{\circ} \mathrm{E}$ as the epicentre of input source models, and then calculated input synthetic waveforms for the stations used in the analysis of the 2013 Balochistan earthquake by using theoretical Green's functions and input source models (Fig. 2b). Theoretical Green's functions were calculated following Kikuchi \& Kanamori (1991) at 0.1-s intervals, and the attenuation time constant $t^{*}$ for the $P$ wave was taken to be $1.0 \mathrm{~s}$. We used the one-dimensional near-source velocity structure (Table 1) used in Avouac et al. (2014) to calculate the theoretical Green's functions. In the calculation of synthetic waveforms, we added an error of Green's function and background noise. As an error of Green's function, we added random Gaussian noise with zero mean and a standard deviation of 5 $\%$ of maximum amplitude of each calculated Green's function. As the background noise, we added random Gaussian noise with zero mean and a standard deviation of $1 \mu \mathrm{m}$ to synthetic waveforms. In the inversion process, we re-sampled the input waveform data at 0.8 -s intervals without applying any filter to both the input waveforms and the theoretical Green's functions.

We prepared 4 kinds of input source models. In the case 1, we adopted the source model of the 2013 Balochistan earthquake as the input source model (Figs. S1a and S2a).

In the case 2, we prepared a reverse faulting model with two large potency density areas on a single, flat-fault plane, $150 \mathrm{~km}$ long and $40 \mathrm{~km}$ wide, with a strike of $90^{\circ}$ and a dip of $45^{\circ}$, which was discretized into $10 \mathrm{~km} \times 10 \mathrm{~km}$ source knots and a depth of $25 \mathrm{~km}$ was adopted as the hypocentral depth (Figs. S3a and S4a). We assumed a total duration of $10 \mathrm{~s}$ of the input potency-rate-density function at each source knot.

In the case 3, we prepared a input source model where $\boldsymbol{M}_{1}, \boldsymbol{M}_{2}, \boldsymbol{M}_{3}$, and $\boldsymbol{M}_{5}$ (Fig. 1a) dominate focal mechanisms of four large potency density areas on a single, flat-model plane, $190 \mathrm{~km}$ long and $50 \mathrm{~km}$ wide, with a strike of $180^{\circ}$ and a dip of $0^{\circ}$, which was discretized into $10 \mathrm{~km} \times 10 \mathrm{~km}$ source knots and a depth of $25 \mathrm{~km}$ was adopted as the hypocentral depth (Figs. S5a and S6a). We assumed a total duration of $10 \mathrm{~s}$ of the input potency-rate-density function at each source knot.

In the inversion process of the case $1-3$, we set a model plane whose geometry is the same as the input one.

In the case 4 , we prepared a left-lateral strike-slip faulting model within a bending fault, combining two, $60 \mathrm{~km}$ long and $30 \mathrm{~km}$ wide, vertical fault planes, striking at $135^{\circ}$ and $180^{\circ}$, respectively (Figs. $\mathrm{S} 7 \mathrm{a}, \mathrm{b})$. The input fault plane was discretized into $10 \mathrm{~km}$ and $5 \mathrm{~km}$ source knots along strike and dip, respectively, and a depth of $30 \mathrm{~km}$ was adopted as the hypocentral depth (Figs. S7b). We assumed a total duration of $20 \mathrm{~s}$ of the input potency-rate-density function at each source knot. In this case, we set a single model plane, $120 \mathrm{~km}$ long and $40 \mathrm{~km}$ wide, with a strike of $165^{\circ}$ and a dip of $0^{\circ}$, horizontally 
covering the input source area (Fig. S7c). The model plane was discretized into $10 \mathrm{~km} \times 10 \mathrm{~km}$ source knots and we took a depth of $30 \mathrm{~km}$ as the initial-rupture depth.

For all cases, we assumed the same total duration between the input and output potency-ratedensity function at each source knot.

The results show that the obtained output source models reproduced the spatiotemporal distribution of focal mechanisms in the input source models (Figs. S1b, S2b, S3b, S4b, S5b, S6b), and the output synthetic waveforms well explained the input waveforms (S2c, S3c, S5c).

In the case 4 , the $45^{\circ}$ change of a strike angle of strike-slip mechanism during the rupture propagation in the input source model can be reproduced in the output source model adopting the horizontal model plane (Figs. S7c, S7d, S8), and the input waveforms are well explained by the output synthetic waveforms (Fig. S7e).

In the case 4, we further evaluated a sensitivity to an assumption of model-plane depth, ranging between $25 \mathrm{~km}$ and $35 \mathrm{~km}$ every $2.5 \mathrm{~km}$. The results show that the distribution of both focal mechanisms and potency density are not significantly affected by the change of initial-rupture depths, although deeper source model shows smaller intensity of overall potency density because an amplitude of Green's function increases with source depth (Fig. S9a). Timing of a peak in the source-time function is shifted in time within $1.6 \mathrm{~s}$ according to the depth of horizontal model plane, which can be explained by travel time difference expected from the difference in depth (Fig. S9b). The peak of the moment rate at around $10 \mathrm{~s}$ in the output source-time function is at most $26 \%$ smaller than that of the input one, because of the discrepancy between the true and the assumed depth range of rupture extent. However, the number and relative amplitudes of peaks in the source-time functions of all output source models are comparable to those of the input source model (Fig. S9b). 
Case 1

(a) Input

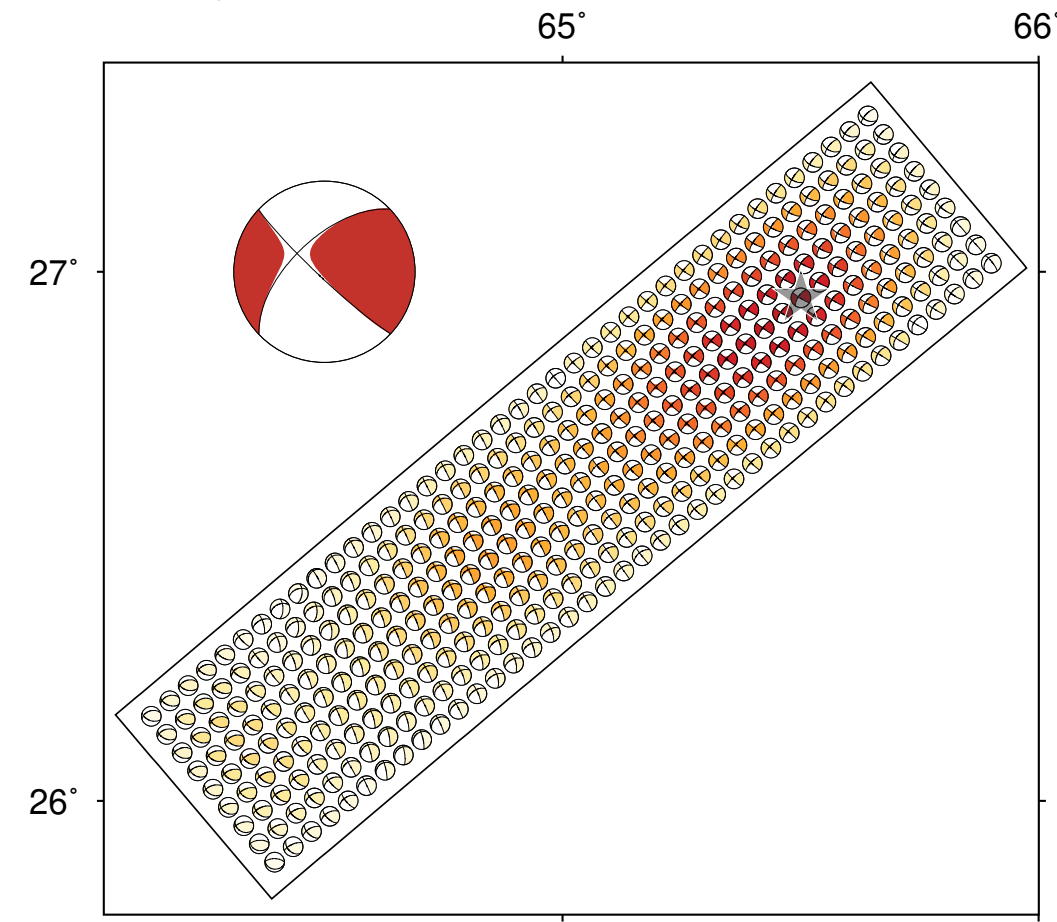

(b) Output

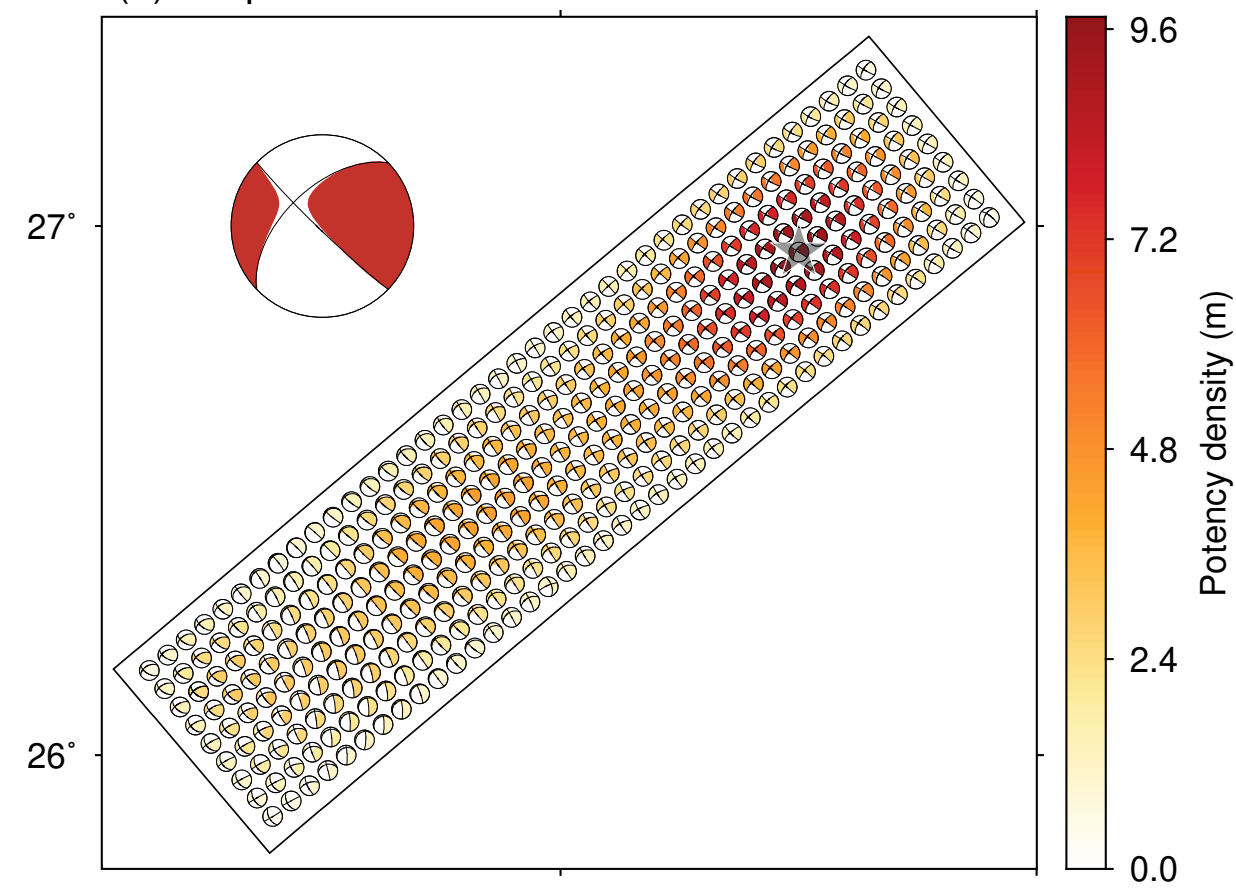

Figure S1. (a) Input source model and (b) Output source model in the case 1. The small beach ball colour shows the potency density. The black line outlines the model fault. The star denotes the epicentre. The large red beach ball represents the total moment tensor obtained by taking a spatial integration of the potency-density tensors. 


\section{Case 1}

(a) Input

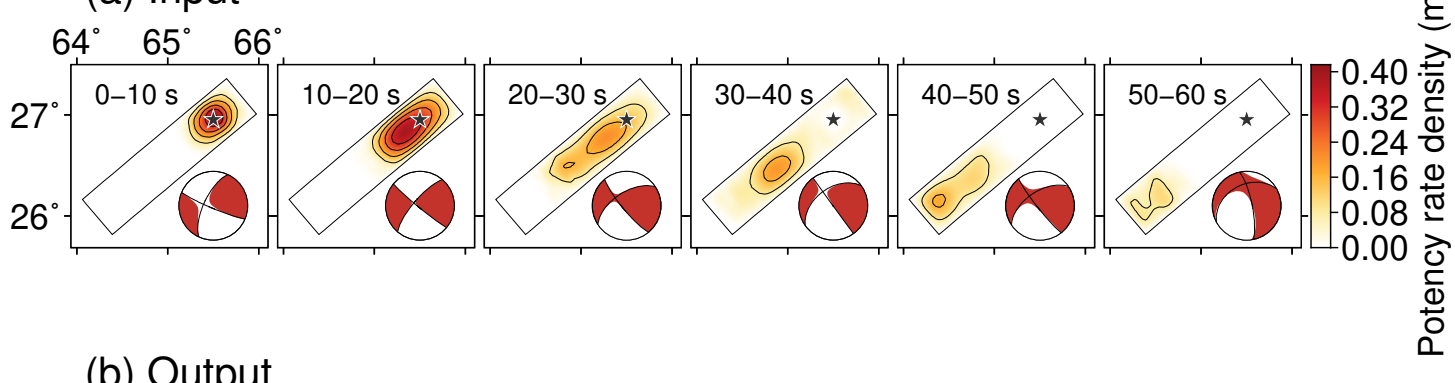

(b) Output

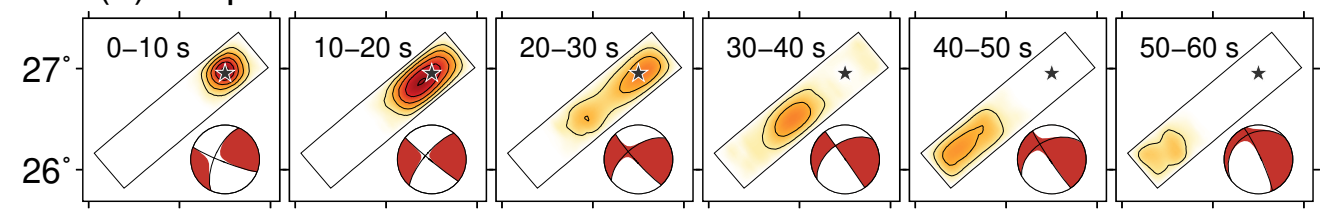

(c)

$\begin{array}{llllll}\text { COLA } & \text { TIXI } & \text { BLLL } & \text { MA2 } & \text { TLY } & \text { ULN } \\ \text { Azi.=13.6 Del.=84.9 } & \text { Azi.=19.8 Del. }=56.3 & \text { Azi. }=23.1 \text { Del. }=69.3 & \text { Azi. }=33.9 \text { Del. }=64.8 & \text { Azi.=38.7 Del }=37.8 & \text { Azi. }=45.8 \text { Del. }=38.5\end{array}$

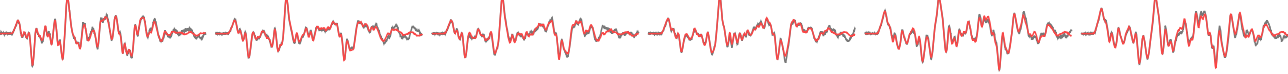

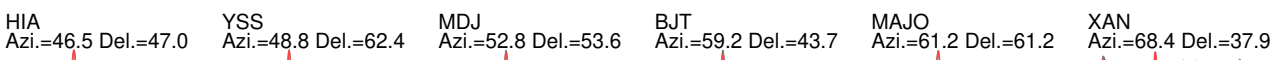

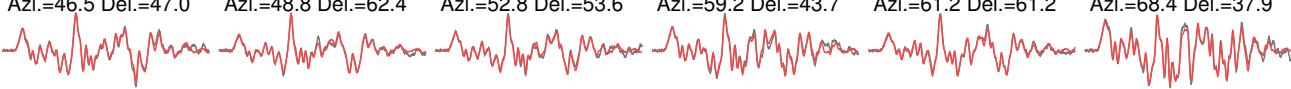

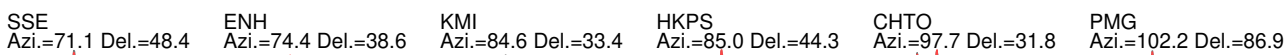

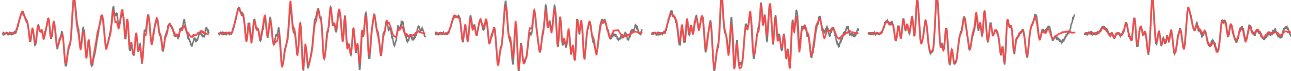

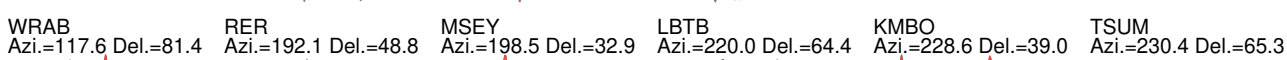

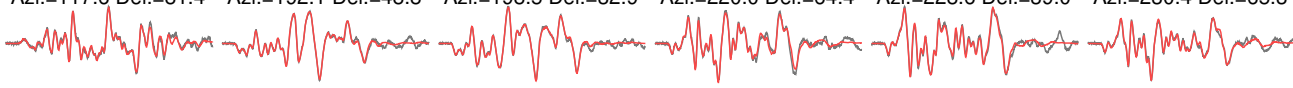

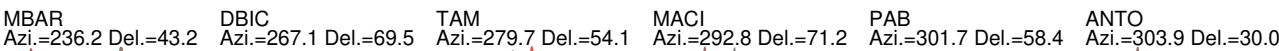

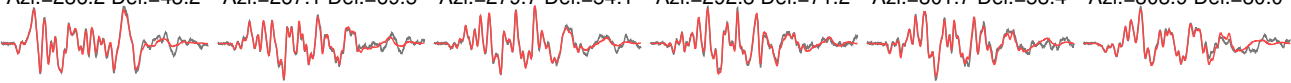

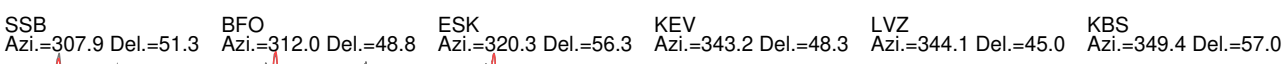

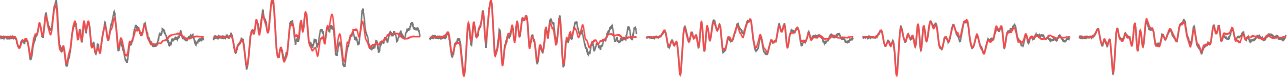

$\begin{array}{lccr}0 & 30 \quad 60 & 90 & \text { Input } \\ \text { Time }(\mathbf{s}) & \text { Output }\end{array}$

Figure S2. Snapshots of (a) input source model and (b) output source model, and (c) waveform fitting at all stations between input and output synthetic waveforms in the case 1. (a, b) Colour shows the potency-rate density. Contour interval is $0.08 \mathrm{~m} / \mathrm{s}$. The black line outlines the model fault. The star denotes the epicentre. The large red beach ball represents the centroid potency-density tensor at each time window. (c) The waveforms are plotted with a sampling interval of $0.05 \mathrm{~s}$. Station code, azimuth, and epicentral distance are shown above the traces. 


\section{Case 2}

(a) Input

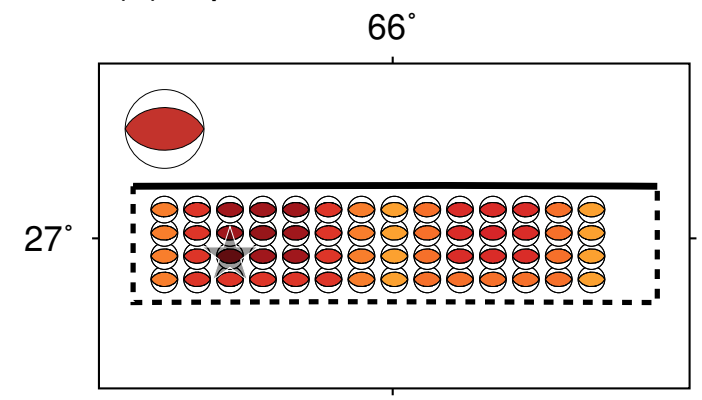

(b) Output

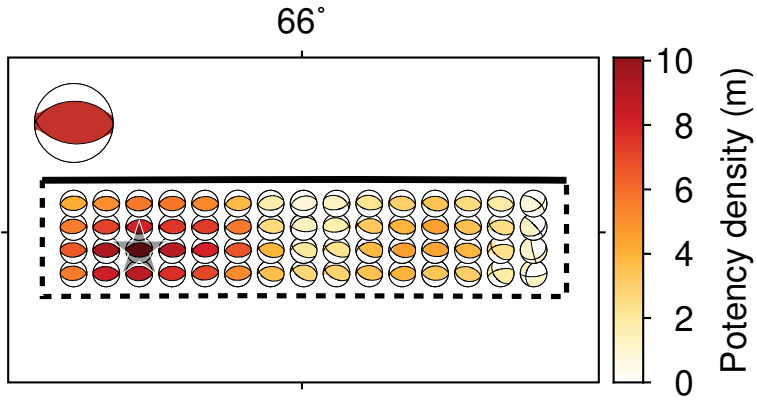

(c)

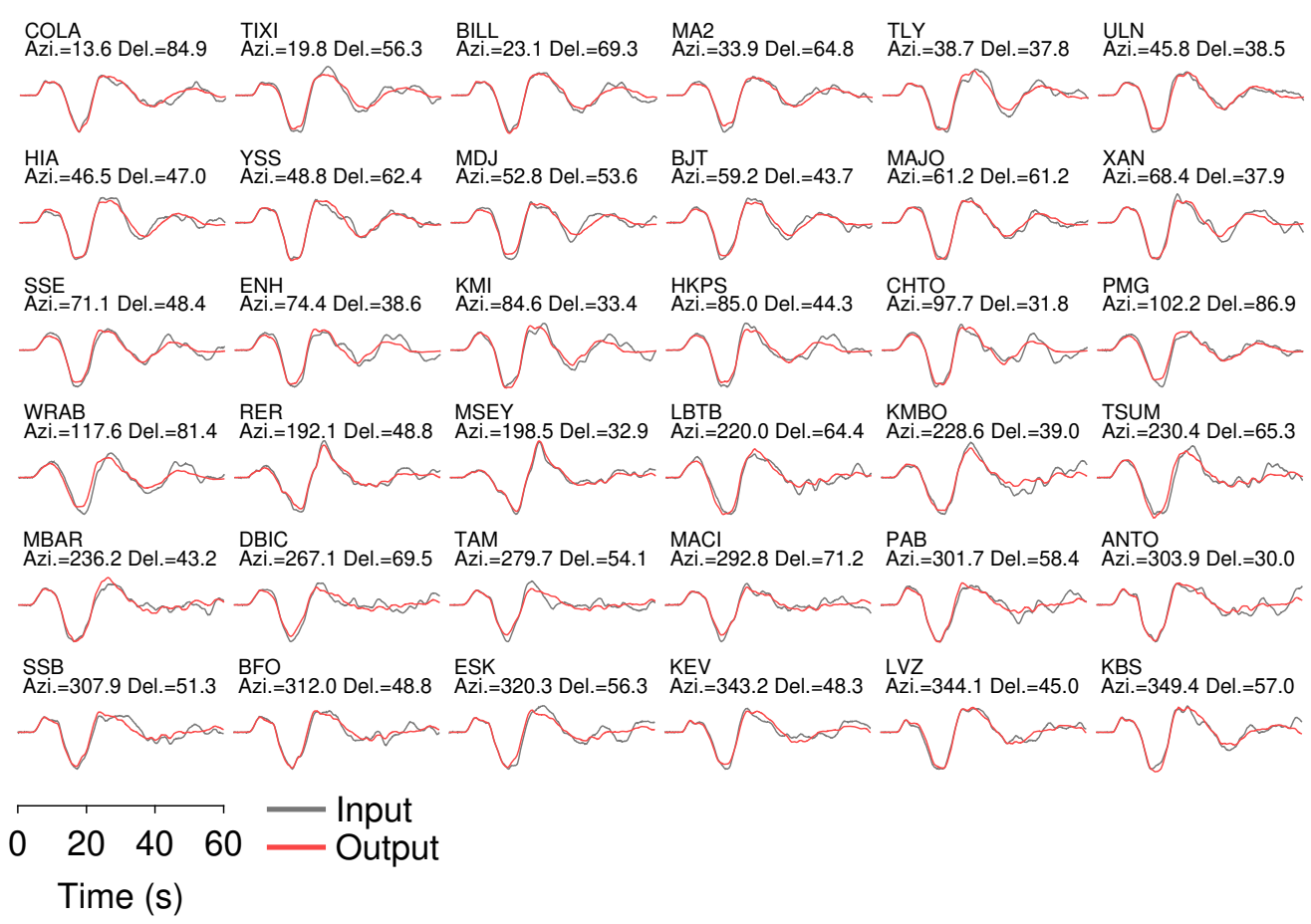

Figure S3. (a) Input source model, (b) Output source model, and (c) waveform fitting at all stations between input and output synthetic waveforms in the case 2. (a, b) The beach ball colour shows the potency density. The dashed line outlines the model fault, and the bold black line shows the top of the model fault, respectively. The star denotes the epicentre. The large red beach ball represents the total moment tensor obtained by taking a spatial integration of the potency-density tensors. (c) The waveforms are plotted with a sampling interval of $0.05 \mathrm{~s}$. Station code, azimuth, and epicentral distance are shown above the traces. 


\section{Case 2}

(a) Input

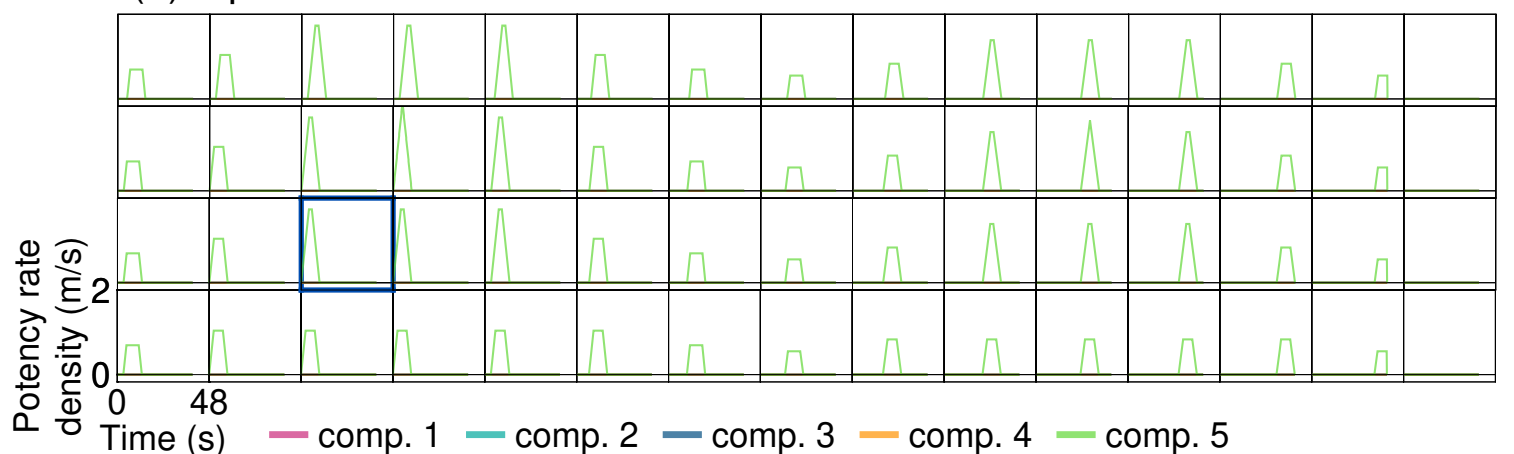

(b) Output

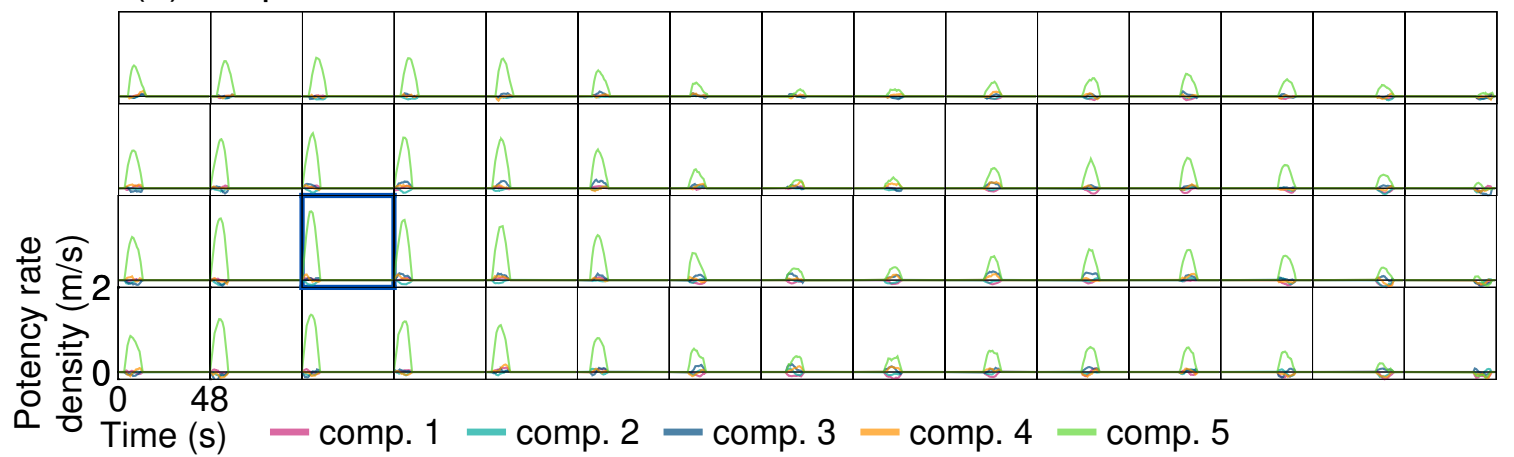

Figure S4. (a) Input and (b) output potency-rate-density functions on an assumed model fault in the case 2. The sub-fault outlined by blue line shows the initial rupture point. Potency-rate-density functions for all basis double-couple components are represented as different colour traces. 


\section{Case 3}

(a) Input

$65^{\circ}$

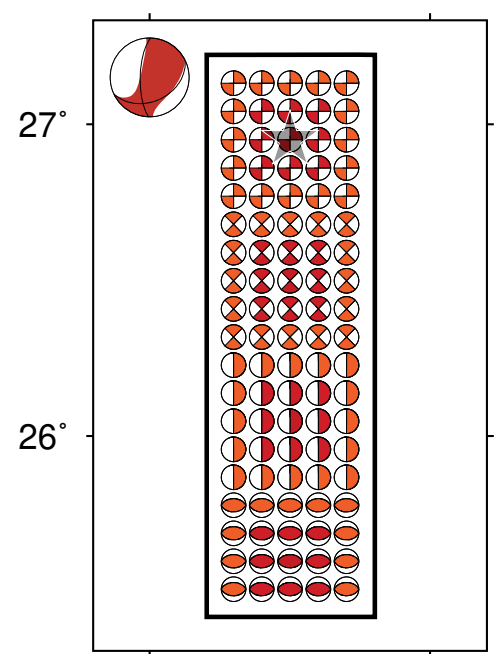

(b) Output

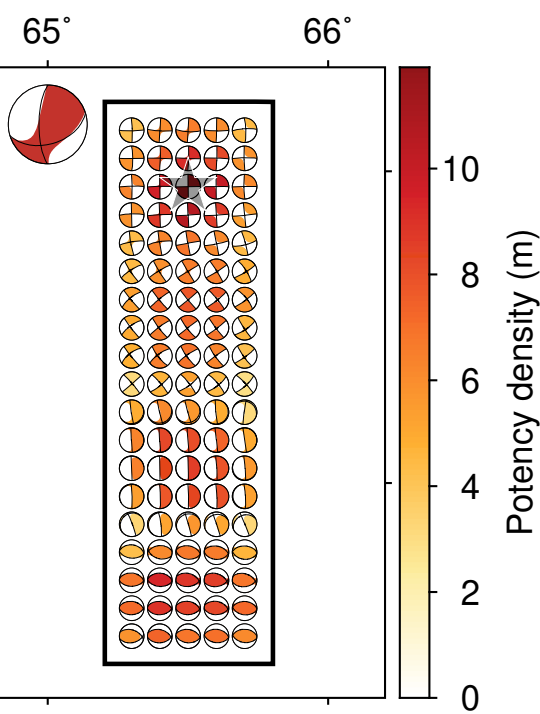

(c)

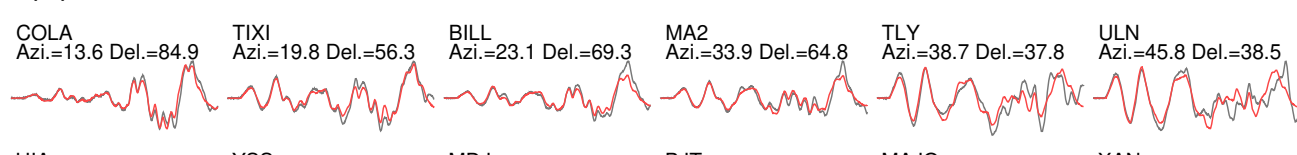

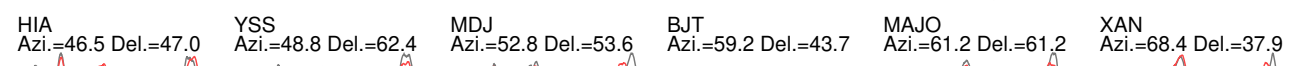
Azi.=46.5 Del.=47.0 Azi.=48.8 Del.=62.4 Azi.=52.8 Del.=53.6 Azi.=59.2 Del.=43.7 Azi.=61.2 Del.=61.2 Azi.=68.4 Del.=37.9

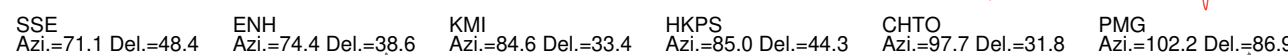

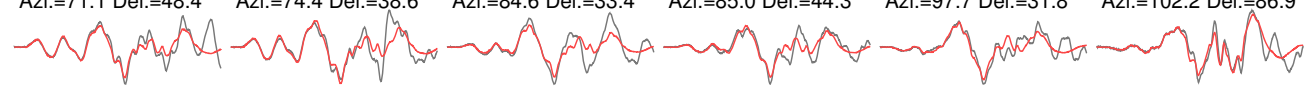

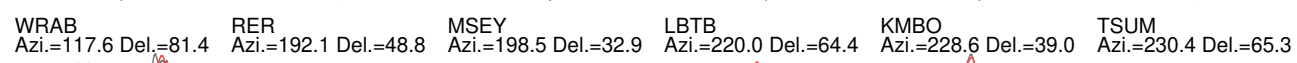

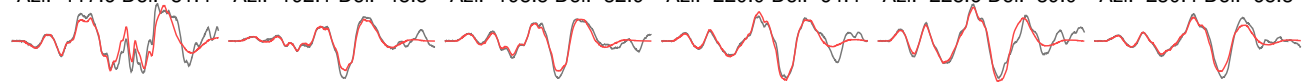

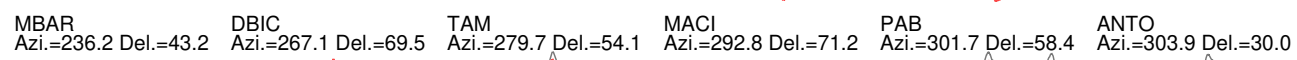
Azi.=236.2 Del.=43.2 Azi.=267.1 Del.=69.5 Azi.=279.7 Del.=54.1 Azi.=292.8 Del.=71.2 Azi.=301.7 Del.=58.4 Azi.=303.9 Del.=30.0

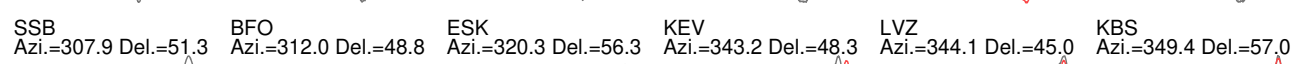

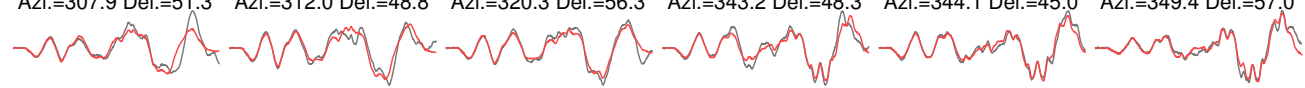

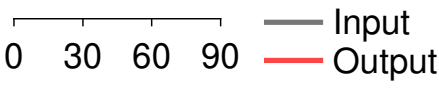

Time (s)

Figure S5. (a) Input source model, (b) Output source model, and (c) waveform fitting at all stations between input and output synthetic waveforms in the case 3. (a, b) The beach ball colour shows the potency density. The dashed line outlines the model fault, and the bold black line shows the top of the model fault, respectively. The star denotes the epicentre. The large red beach ball represents the total moment tensor obtained by taking a spatial integration of the potency-density tensors. (c) The waveforms are plotted with a sampling interval of $0.05 \mathrm{~s}$. Station code, azimuth, and epicentral distance are shown above the traces. 


\section{Case 3}

(a) Input

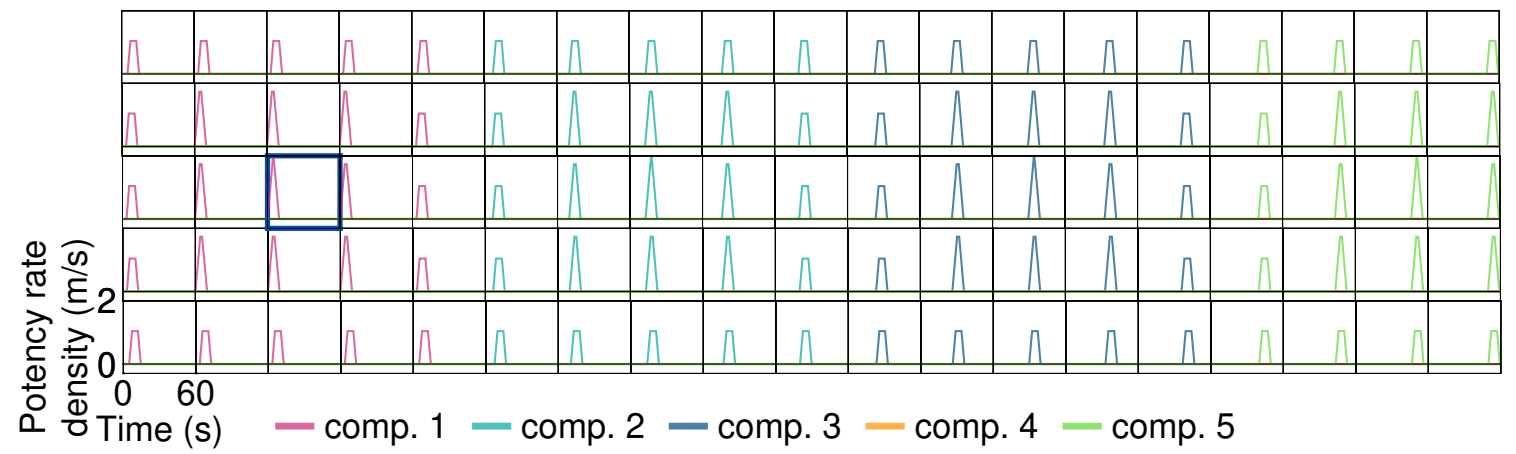

(b) Output

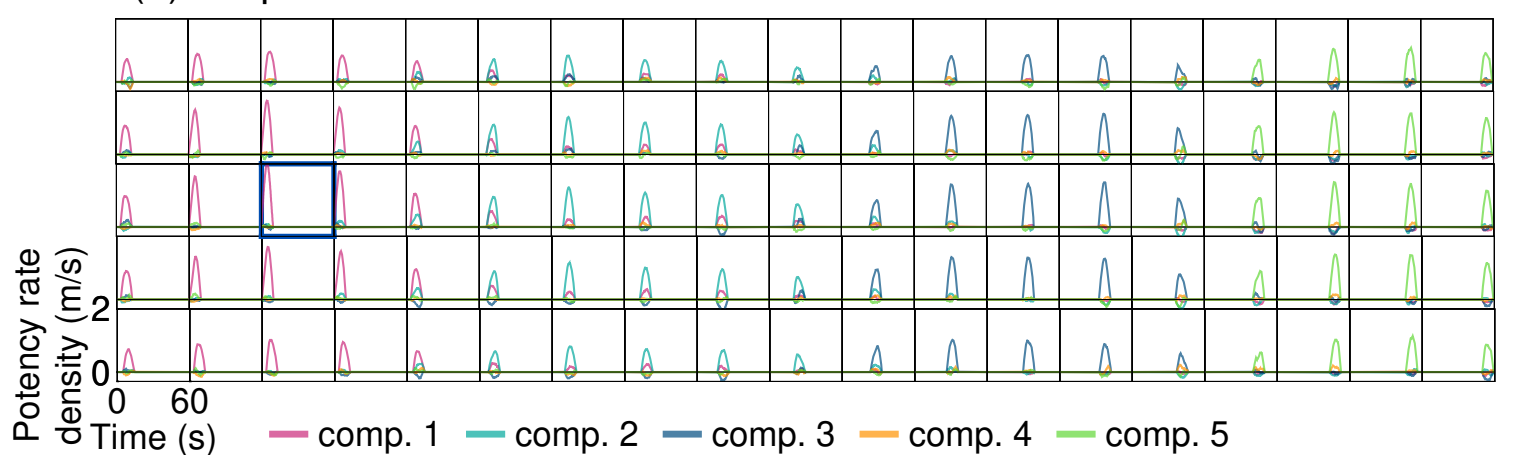

Figure S6. (a) Input and (b) output potency-rate-density functions on an assumed model fault in the case 3. The sub-fault outlined by blue line shows the initial rupture point. Potency-rate-density functions for all basis double-couple components are represented as different colour traces. 


\section{Case 4}

(a) Input

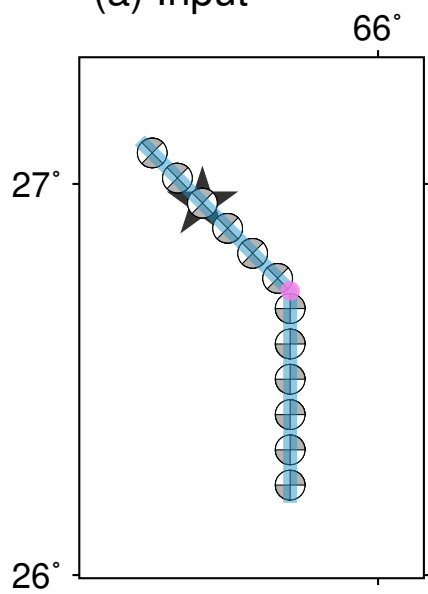

(c) Output

Depth: $30 \mathrm{~km}$

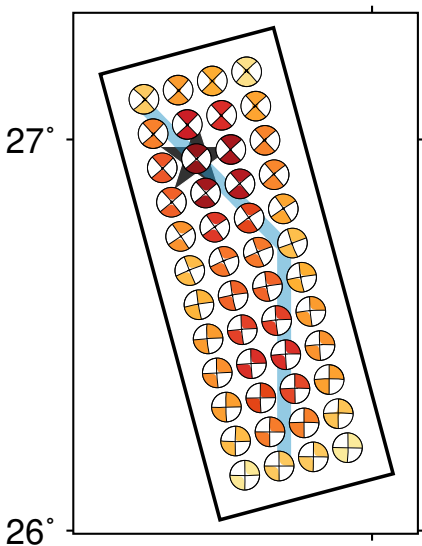

(b) Input

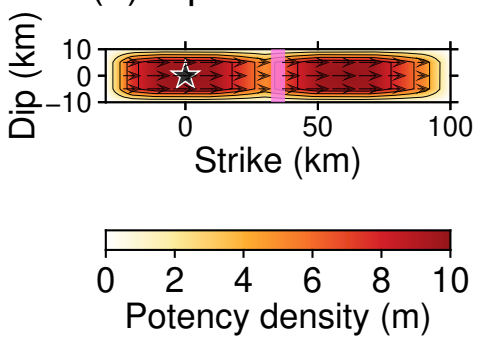

(d) Output

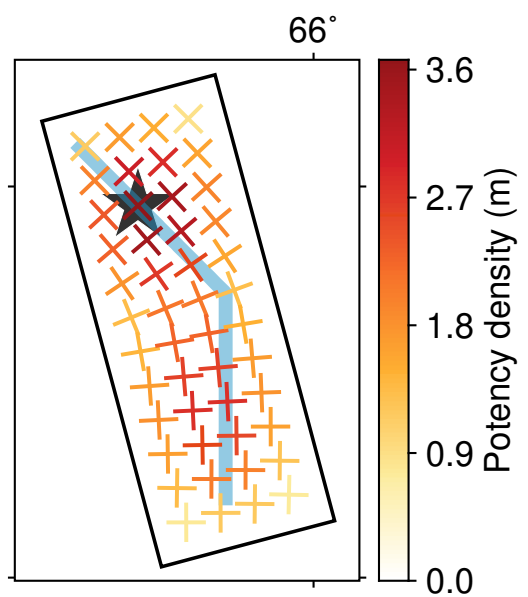

(e)

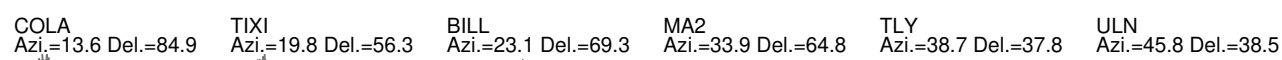

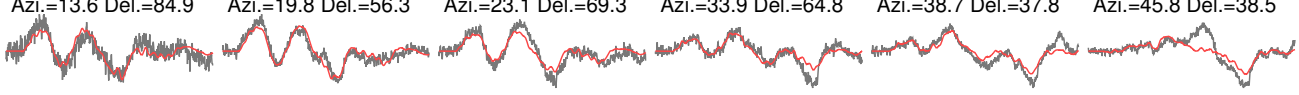

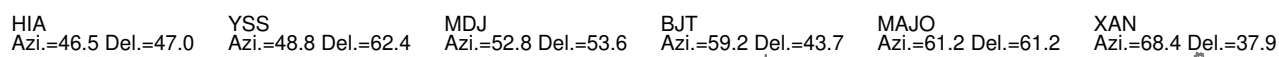

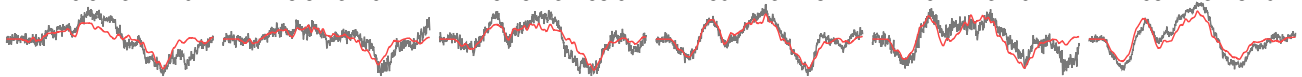

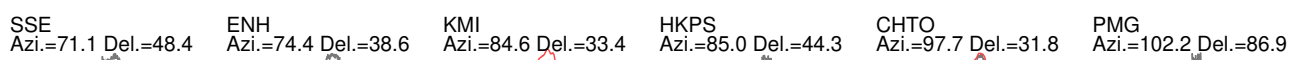
人)

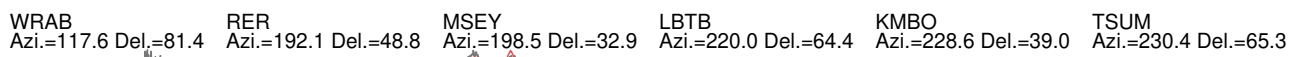

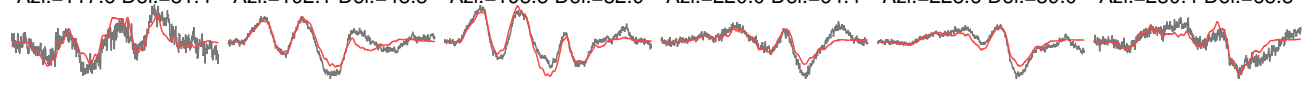

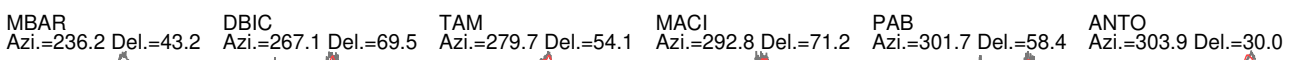

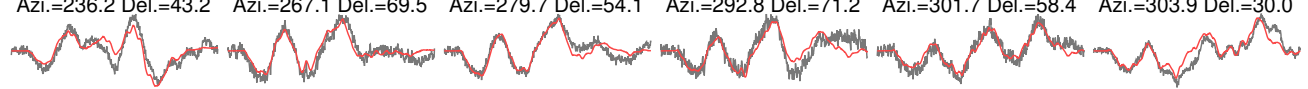

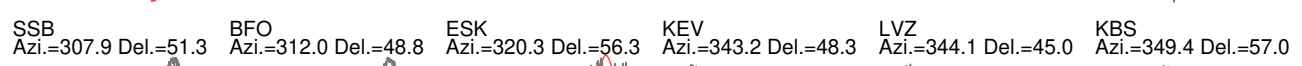

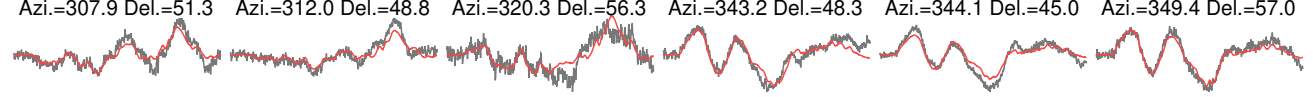
$0 \underset{1}{204060}$ — Input
Time (s) 
Figure S7. (a) Fault geometry and focal mechanisms of the input source model, (b) distribution of potency density and slip angles on an assumed fault plane, (c) output source model, (d) distribution of strike angles extracted from the output source model, and (e) waveform fitting at all stations between input and output synthetic waveforms in the case 4. (a) The blue line represents the top of a fault plane of the input source model. The star denotes the epicentre. The pink circle denotes the point where strike angle of an assumed fault plane changes. Beach balls show assumed focal mechanisms. (b) The black arrow denotes the slip vector. The star denotes the initial rupture point. The pink line represents the boundary where strike angle of an assumed fault plane changes. Colour shows the potency density. Contour interval is $2 \mathrm{~m}$. (c, d) Colour shows the potency density. The star denotes the epicentre. The black line outlines the model fault. The blue line represents the top of a fault plane of the input source model. The small beach ball, shown in (c), shows the focal mechanism at each source knot, plotted using a lower-hemisphere stereographic projection. Direction of the bar shown in (d) represents the strike angle obtained from the focal mechanism shown in (c). (e) The waveforms are plotted with a sampling interval of $0.05 \mathrm{~s}$. Station code, azimuth, and epicentral distance are shown above the traces. 


\section{Case 4}
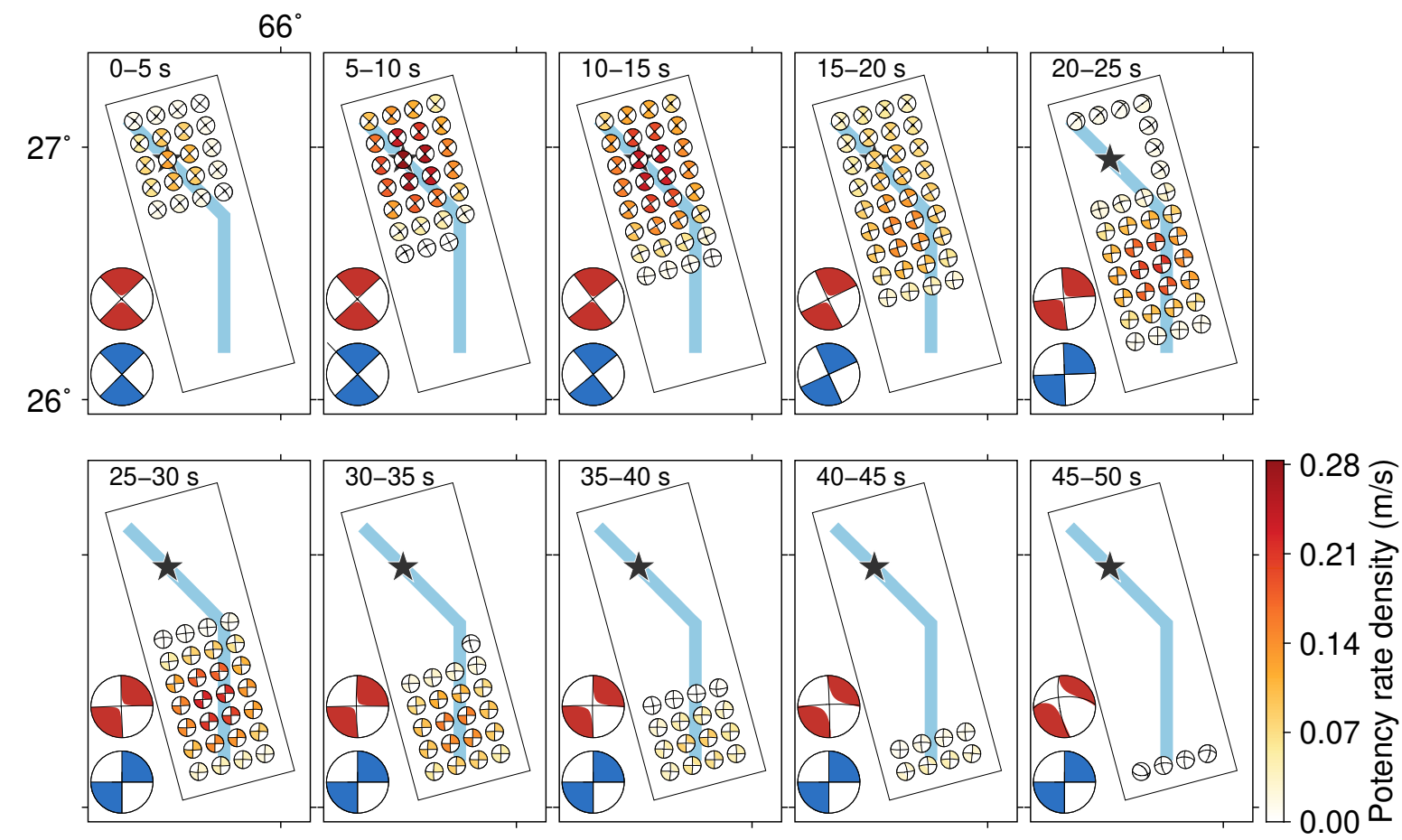

Figure S8. Snapshots of output source model. Colour shows the potency-rate density in the case 4. The star denotes the epicentre. The black line outlines the model fault. The blue line represents the top of a fault plane of the input source model. The small beach ball shows the focal mechanism at each source knot, plotted using a lower-hemisphere stereographic projection. The large blue and red beach ball are the centroid potency-density tensor at each time window of the input and output source models, respectively. 


\section{Case 4}

(a)

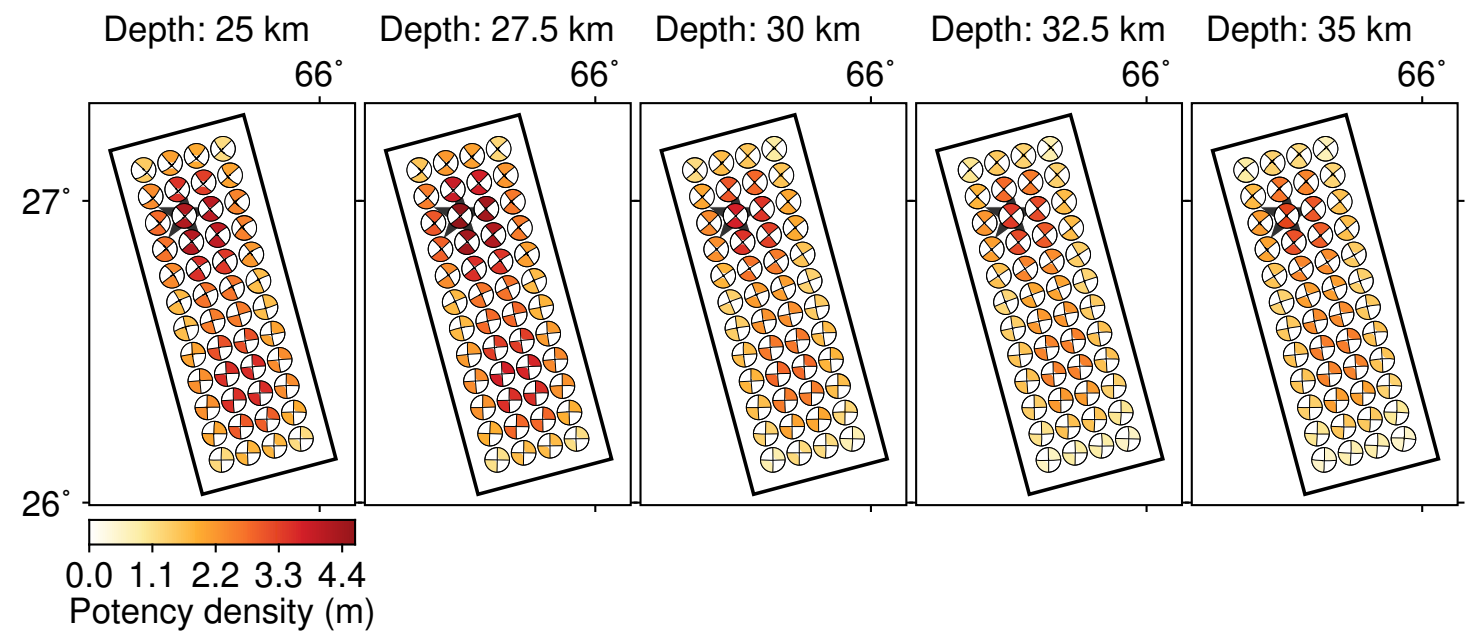

(b)

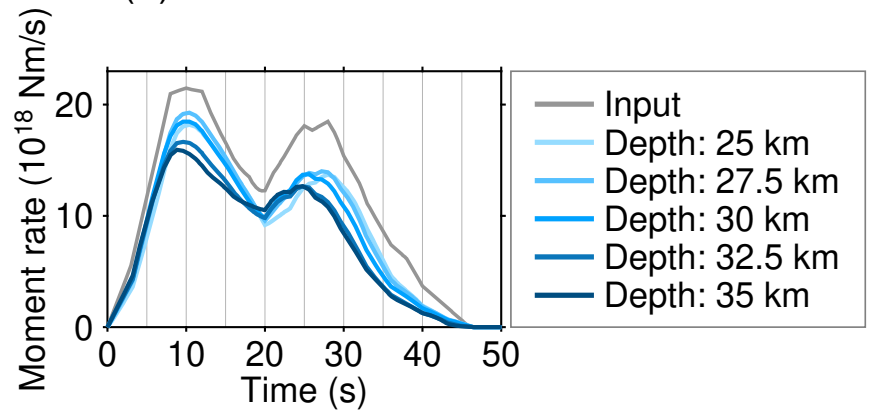

Figure S9. (a) Output source models with different initial rupture depths and (b) their moment-rate functions in the case 4. (a) Colour shows the potency-rate density. The star denotes the epicentre. The black line outlines the model fault. The small beach ball shows the focal mechanism at each source knot, plotted using a lowerhemisphere stereographic projection. 


\section{K. Shimizu, Y. Yagi, R. Okuwaki, and Y. Fukahata}

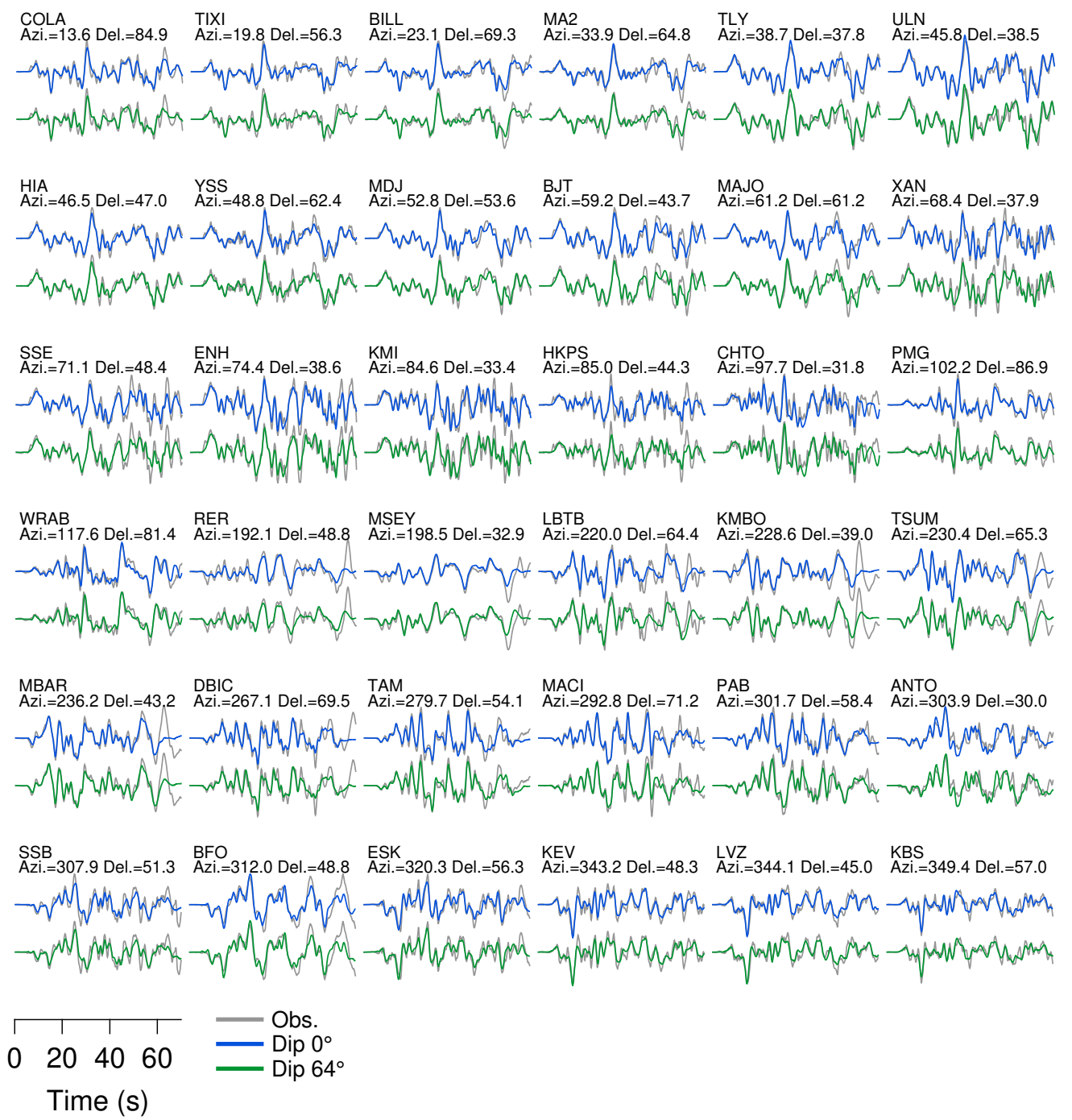

Figure S10. Waveform fitting at all stations between observed (grey line) and synthetic waveforms for the model planes dipping $0^{\circ}$ (top blue line) and dipping $64^{\circ}$ (bottom green line). The waveforms are plotted with a sampling interval of $0.05 \mathrm{~s}$. Station code, azimuth, and epicentral distance are shown above the traces. 


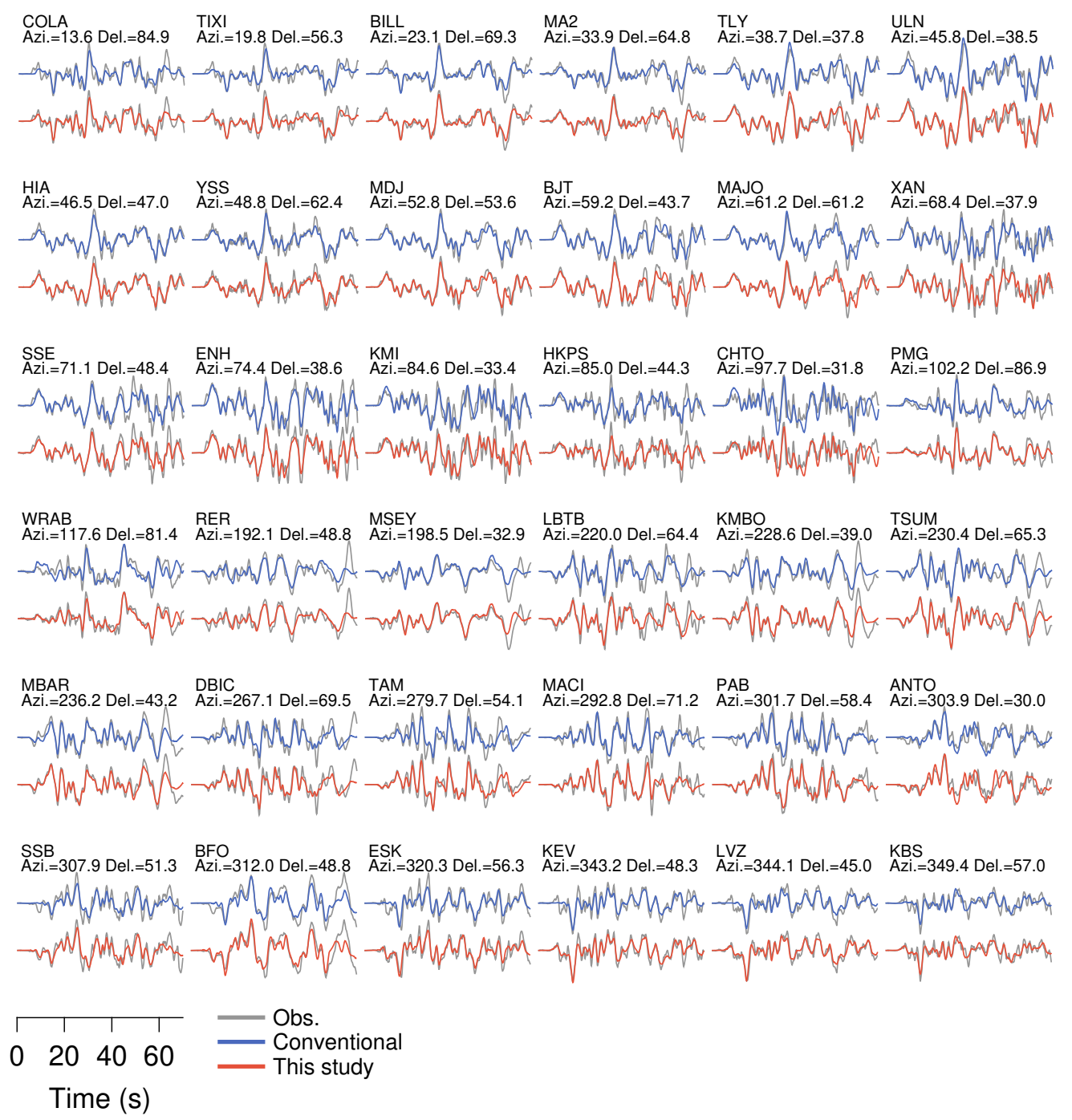

Figure S11. Waveform fitting at all stations between observed (grey line) and synthetic waveforms for the source models obtained by the conventional method (top blue line) and our method developed in this study (bottom orange line). The waveforms are plotted with a sampling interval of $0.05 \mathrm{~s}$. Station code, azimuth, and epicentral distance are shown above the traces. 
(a) Neglecting uncertainty in Green's function $65^{\circ}$

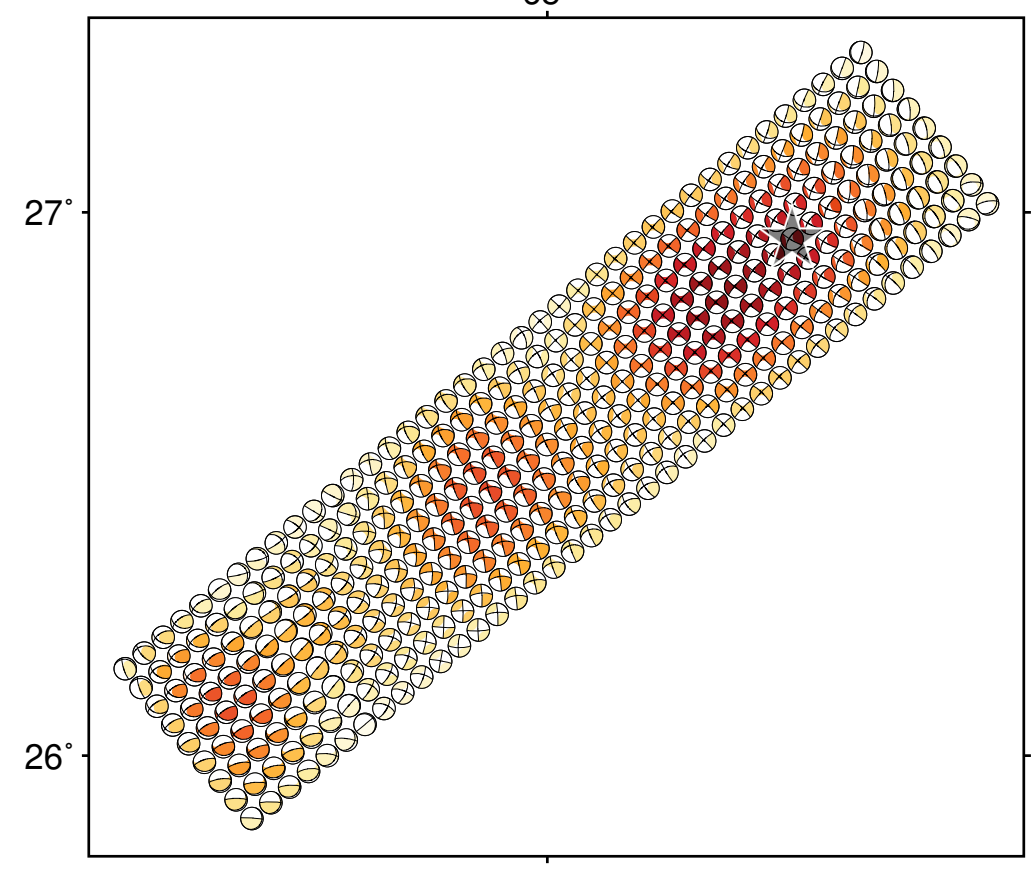

(b) This study: Introducing uncertainty in Green's function

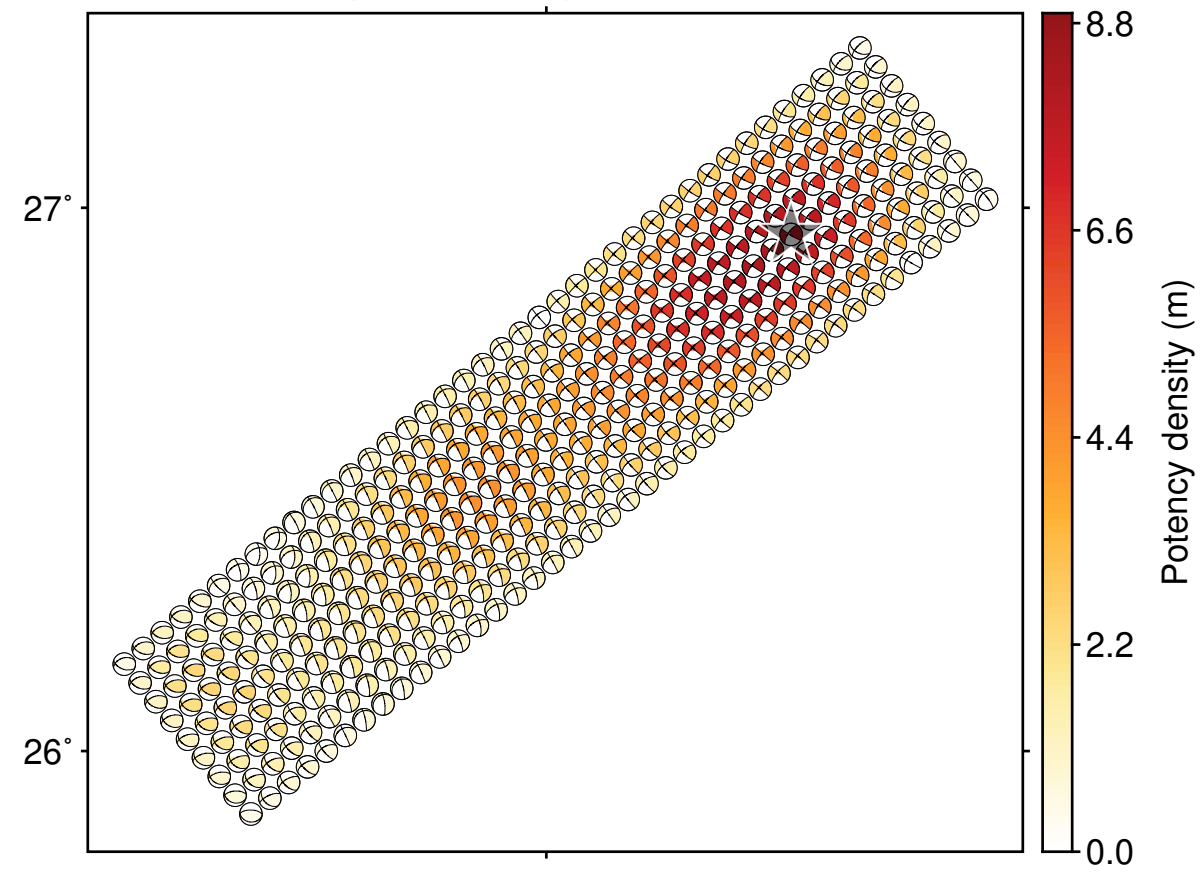

Figure S12. Spatial distribution of the potency-density tensors obtained by using (a) the formulation that neglects uncertainty of Green's function and (b) the one developed in this study introducing uncertainty of Green's function into the data covariance matrix. The small beach ball shows the focal mechanism at each source knot, plotted using a lower-hemisphere stereographic projection. The star denotes the epicentre. The beach ball colour shows the potency density. 


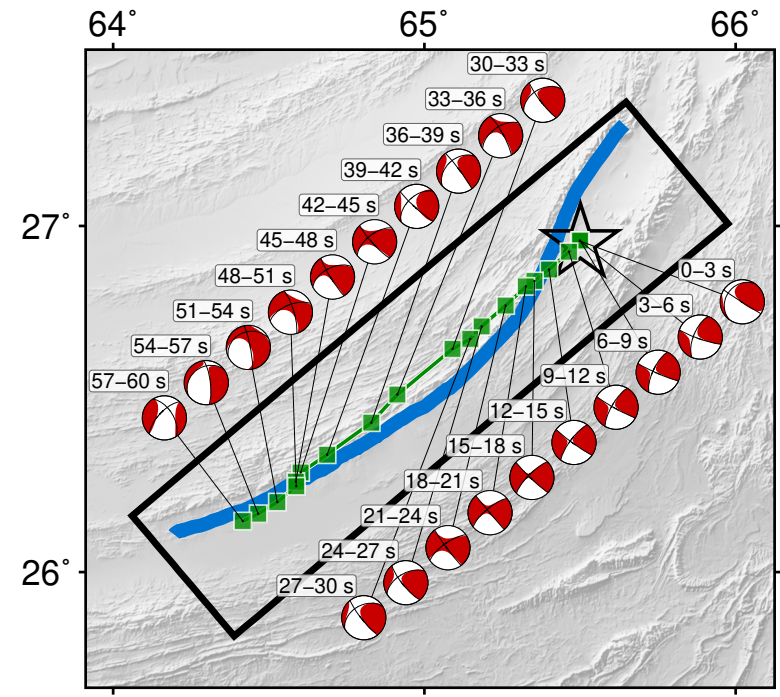

Figure S13. The evolution of the centroid of the potency-rate-density tensors. The centroid locations (green squares) of the potency-rate density and its potency-density tensor is shown at each time window, along with the distance between the neighbouring centroid locations and the corresponding time window for estimation of the centroid location. The blue line represents the surface-rupture trace measured by Zinke et al. (2014). The rectangle outlines the model plane. The star denotes the epicentre.

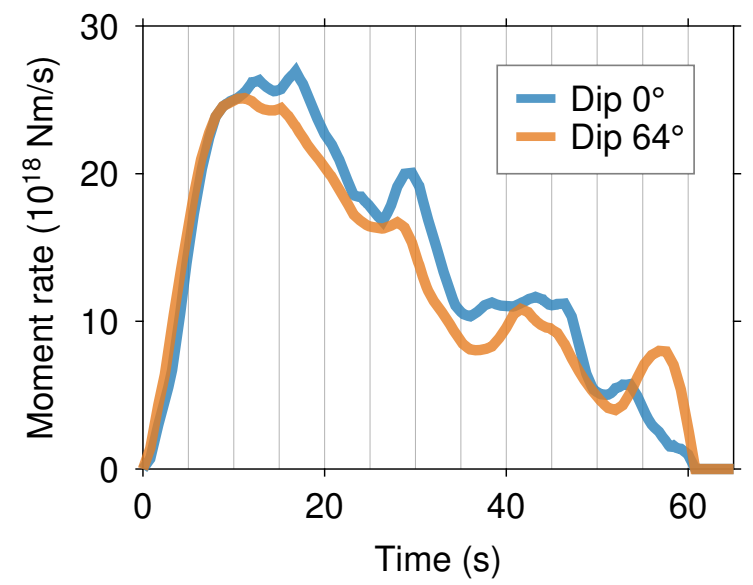

Figure S14. Moment-rate functions for the model planes dipping $0^{\circ}$ (blue line) and $64^{\circ}$ (orange line). 


\section{REFERENCES}

Avouac, J. P., Ayoub, F., Wei, S., Ampuero, J. P., Meng, L., Leprince, S., Jolivet, R., Duputel, Z., \& Helmberger, D., 2014. The 2013, Mw 7.7 Balochistan earthquake, energetic strike-slip reactivation of a thrust fault, Earth and Planetary Science Letters, 391, 128-134.

Kikuchi, M. \& Kanamori, H., 1991. Inversion of Complex Body Waves-III, Bulletin of the Seismological Society of America, 81(6), 2335-2350.

Zinke, R., Hollingsworth, J., \& Dolan, J. F., 2014. Surface slip and off-fault deformation patterns in the 2013 MW7.7 Balochistan, Pakistan earthquake: Implications for controls on the distribution of near-surface coseismic slip, Geochemistry, Geophysics, Geosystems, 15(12), 5034-5050. 